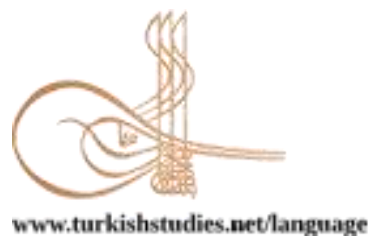

www.turkishstudies.net/language
Turkish Studies - Language and Literature

\author{
eISSN: 2667-5641
}

Research Article / Araştırma Makalesi

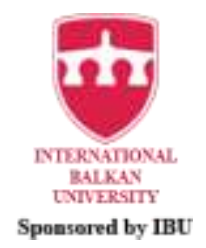

\title{
Ladik (Samsun) Ağzındaki Arkaik Unsurlar Üzerine*
}

\author{
The Archaic Elements in Ladik (Samsun) Dialect
}

\author{
Adalet Gül Özgül ${ }^{* *}$
}

\begin{abstract}
Ladik is one of the seventeen districts of Samsun province, which is located within the borders of the Central Black Sea according to the current geographical classification. Also, in terms of geographical location, it is located in the interior of Samsun. Ladik's history dates back to antiquity and the most comprehensive information about Ladik is found in Evliya Çelebi's work "Seyahatname" and in the works "Amasya Tarihi" of Amasya Abdizâde Hüseyin Hüsameddin Efendi. The works contain remarkable information and findings in terms of Ladik's name, history, economy, population, promenade locations and architectural features. Turkey Turkish dialects are separated from the standard language in terms of the basic characteristics. It is a legacy in terms of phonetics, morphological and vocabulary, as it contains words and suffixes that do not use standard language. For this reason, archaic elements are used when analyzing Turkish in terms of phone, morpho and vocabulary. Recently, the interaction between Turkey Turkish dialects and standard language has increased thanks to the increased communication opportunities, education and teaching. As a result of this interaction, a number of elements in the dialect began to disappear over time. In this study were examined the archaic elements found in the Ladik (Samsun) dialect, one of the Turkey Turkish dialects. Since Ladik (Samsun) dialect has a dialect structure that is influenced by both Oghuz and Kipchak Turkish, some words with archaic elements also have figures of Kipchak Turkish in their phone and vocabulary descriptions. The archaic words examined were given starting from the Old Turkish period to the early era of Western Turkish period. Some words are also given as they appear in historical Turkish dialects.
\end{abstract}

Structured Abstract: Ladik, which was part of Amasya province for a period, is now one of the 17 districts of Samsun and has a special importance in terms of its historical, geographical location and transportation. Ladik's history dates back to antiquity and it is also important because it is one of the first Turkish settlements in the Black Sea. The most comprehensive information about Ladik is found in Evliya Çelebi's work "Seyahatname" and in the works "Amasya Tarihi" of Amasya Abdizâde Hüseyin Hüsameddin Efendi.

Turkey has attracted the attention of foreigners due to factors such as its geographical location, deeprooted history, society formed by the combination of various ethnics and diversity of culture. For this reason, various researches and studies have been carried out to reveal the history, culture and importance of the Turkish language and to bring it together with interested people. One of the researches and studies is language and culture research. One of the sub-studies examining these language and cultural studies is dialect research.

\footnotetext{
* Bu makale yazarın Prof. Dr. Funda TOPRAK danışmanlığında tamamladığı "Ladik (Samsun) Ağzı" başlıklı doktora tezinden üretilmiştir.

** Doktora Öğrencisi, Ankara Yıldırım Beyazıt Üniversitesi, Sosyal Bilimler Enstitüsü, Türk Dili ve Edebiyatı ABD. PhD Student, Ankara Yildırım Beyazıt University, Graduate School of Social Sciences, Turkish Language and Literature. ORCID 0000-0002-4022-9454 adaletgulozgul@gmail.com

Cite as/ Atıf: Özgül, A. G. (2020). Ladik (Samsun) ağzındaki arkaik unsurlar üzerine. Turkish Studies - Language, 15(2), 787-803. https://dx.doi.org/10.29228/TurkishStudies.43852

Received/Geliş: 15 May/Mayıs 2020

Accepted/Kabul: 20 June/Haziran 2020

Copyright (C) INTAC LTD, Turkey
} 
According to the previous paragraph, the first interest in dialect research was realized by foreign researchers, and by local researchers after the 1940s. With the participation of local researchers, dialect research has gained speed and language and culture values have been recorded and preserved. However, despite the positive effects of the rapidly developing technological developments in recent years, their negative effects have also emerged. The negative effects of technology show their effects on language and culture materials, causing them to disappear over time.

Turkey Turkish dialects are one of the most important parts of our language in terms of both phonetic, morphological knowledge and the presence of vocabulary. In terms of phone, morphological and vocable, it is possible to see archaic elements in Turkey Turkish dialects based on Oghuz Turkish. Therefore, archaic features are often used when referring to the equivalence of meaning in phone, morphological and words of Turkey Turkish dialects.

In this study were examined the archaic elements found in the Ladik (Samsun) dialect, one of the Turkey Turkish dialects. In addition, Turkish dialects were mentioned in relevant parts of this study. The archaic elements in the words identified in the Ladik (Samsun) dialect are given in historical order starting from old Turkish. Archaic elements are given according to S. G. Clauson's An Etymological Dictionary of PreThirteenth Century Turkish (EDPT), Talat Tekin's Orhon Yazıtlarl “Orkhon Inscriptions” (OY), A. Von Gabain's Eski Türkçenin Grameri “Grammar of Old Turkish” (ETG), Ahmet Caferoğlu’s Eski Uygur Türkçesi Sözlüğ̈̈ “Old Uyghur Turkish Dictionary” (EUTS), Kutadgu Bilig (KB) and Divanü Lügati't-Türk (DLT) are the main works of Qarakhanid Turkish period, Nehcü'l Frād ${ }_{\top} s$ III Dizin-Sözlük "Nehcü'l Ferād $\mathrm{T}$ III Directory-Dictionary" (NFD-S), indexed by Aysu Ata, Kıpçak Türkçesi Sözlüğ̈̈ "Kipchak Turkish Dictionary” (KTS) of Recep Toparli et al., Erol Öztürk’s Eski Anadolu Türkçesi El Kitabı "Old Anatolian Turkish Handbook” (EATEK) and Cem Dilçin's Yeni Tarama Sözlüğü “New Scanning Dictionary” (YTS).

In this study, 80 words were examined that retain their archaic features in Ladik (Samsun) dialect. The dark colored ones are given in the form of spoken form in the dialect, while the contents in parentheses are given their original form. Some of the words identified in dialect are given in both the old Turkish form and the Oghuz Turkish form. Since some of the words studied have more than one meaning, what sense is used in the Ladik (Samsun) dialect is given in the footnotes; acug/acu $\Gamma$ "sour", aşlı $\dot{g}$ "wheat, wheat berry". Sometimes the phrase in dialect of the word illig <il+lik "peace, relationship", $o_{\Gamma \zeta s} a C ̧ \iota$ "resembling, like" is explained by giving the whole state.

The difference in the spelling of the phonetics are remarkable, since the spelling of the works exemplified in the description of the words examined in the archaic direction is followed. In the examples, ä for / e / phone; é, è for closed /e/ phone; $\mathrm{y}, \mathrm{ng}, \square, \mathrm{L}$ consonant for nasal /n/ are used. Another remarkable feature is Kipchak Turkish. Turkey Turkish dialects general Oghuz contains elements. The Ladik(Samsun) dialect, which was examined from the archaic point of view, was found to preserves both Oghuz and Kipchak Turkish characteristics. The " $\dot{\mathrm{g}}>\mathrm{v}$ " phonetic change especially seen in Kipchak Turkish continued by showing its effect in this dialect.

As a result of this study, the following results have been achieved.

1. Ladik (Samsun) dialect, which is examined archaic in terms of phone and vocabulary, has been determined to have the characteristics of both Oghuz and Kipchak Turkish.

2. In Old Turkish, the vocalised, non-continuant, unmediae consonant $/ \mathrm{b} /$ at the beginning of the word is preserved in dialect; bol- "olmak", biş- "pişmek".

3. In Old Turkish, the unvocalised, non-continuant, unmediae consonant $/ \mathrm{k} /$ at the beginning of the word is preserved in dialect; kel- "gelmek", kece "gece".

4. In Old Turkish, the vocalised, continuant, liquid consonant $/ \mathrm{m} /$ at the beginning of the word is preserved in dialect; men "ben", $m u$ "bu".

5. In Old Turkish, the unvocalised, non-continuant, unmediae consonant $/ \mathrm{t} /$ at the beginning of the word is preserved in dialect; $t i$ - "demek", tol- "dolmak".

6. It is determined that the labialisation in Old Turkish continues in dialect; berü "beri, öte", uçun, üçün "için".

7. In terms of vocabulary, the meanings were preserved in dialect.

Keywords: Old Turkish, Archaic, Turkey Turkish Dialects, Ladik (Samsun) Dialect, Vocabulary, Phonetic. 
Öz: Ladik, bugünkü coğrafi sınıflandırmaya göre Orta Karadeniz sınırları içerisinde yer almakta olan Samsun ilinin on yedi ilçesinden biridir ve coğrafi konum özelliği bakımından ise Samsun'un iç kısmında yer alır. Tarihi, antik çă̆ dönemine dayandığı bilinen Ladik'le ilgili en kapsamlı bilgiler Evliya Çelebi’nin "Seyahatname" adlı eseri ve Amasyalı Abdizâde Hüseyin Hüsameddin Efendi'nin "Amasya Tarihi" adlı eserlerinde bulunmaktadır. Eserlerde Ladik'in adı, tarihi, ekonomisi, nüfusu, mesire yerleri ve mimari özelliği gibi yönlerden dikkat çekici bilgi ve bulgular yer almaktadır. Temel özellikleri bakımından ölçünlü dilden ayrılan Türkiye Türkçesi ağızlarında ölçünlü dilde kullanılmayan kelimeler ve ekler yaşadığı için ses (fonetik), şekil (morfoloji) ve söz varlığı (leksikoloji) açısından bir mirastır. Bu nedenle Türkçenin ses, şekil ve söz varlığı açısından incelemeleri yapılırken arkaik/eskicil unsurlardan yararlanılır. Son zamanlarda artan iletişim olanakları, eğitim ve öğretim sayesinde Türkiye Türkçesi ağıları ve ölçünlü dil arasındaki etkileşimi artırmıştır. Bu etkileşim neticesinde ağızlara sinmiş olan birtakım unsurlar zamanla yok olmaya başlamıştır. Bu çalışmada Türkiye Türkçesi ağızlarından biri olan Ladik (Samsun) ağzında bulunan arkaik/eskicil unsurlar incelenmiştir. Ladik (Samsun) ağzı hem Oğuz hem de Kıpçak Türkçesinin etkisinde kalan bir ağız yapısına sahip olduğu için arkaik/eskicil unsurlu bazı kelimelerin ses ve söz varlığı dayanan açıklamalarında Kıpçak Türkçesinde bulunan şekillerine de yer verilmiştir. Ele alınan arkaik/eskicil kelimeler Eski Türkçe döneminden başlayarak Batı Türkçesinin ilk dönemlerine kadar ve bazı kelimelerde de tarihî Türk lehçelerinde göründükleri şekilleriyle verilmiştir.

Anahtar Kelimeler: Eski Türkçe, Arkaik/eskicil, Türkiye Türkçesi Ağızları, Ladik (Samsun) Ağzı Söz Varlığı, Ses Bilgisi

\section{Giriş}

Bir dönem Amasya vilayetine bağlı kalan Ladik, Samsun'un 17 ilçesinden biri olmakla birlikte tarihi, coğrafi konumu ve ulaşımı açısından da ayrı bir öneme sahiptir. Tarihi, antik çă̆ dönemine dayandığı bilinen Ladik, Karadeniz'deki ilk Türk yerleşim yerlerinden biri olması bakımından da önemlidir. Özellikle Terme/Ambartepe ve Salıpazarı'nda yapılan arkeolojik kazılar ve Ladik'te ele geçen buluntular sonucunda bu bölgede İskitlerin varlığına işaret ettiği bilinmektedir (Tellioğlu, 2010: 142-144; 2014: 1110). Ladik'le ilgili en kapsamlı bilgi Evliya Çelebi'nin "Seyahatname" adlı eseri ve Amasyalı Abdizâde Hüseyin Hüsameddin Efendi'nin "Amasya Tarihi" adlı eserlerinde bulunmaktadır. Bu eserlerde Ladik'in adı, tarihi, coğrafi konumu, köy ve mahalle isimleri camileri, medrese ve tekkeleri ve nüfusu gibi bilgilerin yanında Ladik'in Çelebi Sultan Mehmet Han ve şehzadesi ile Sultan İkinci Bayezid Han ve şehzadeleri Amasya'da valilikte bulundukları esnada yazlık saray vazifesini gördüğünden de söz edilmektedir. ${ }^{1}$

Türkiye, coğrafi konumu, köklü tarihi, çeşitli etniklerin birleşimiyle oluşan toplumu bünyesinde barındırması ve bunun sonucunda da oluşan kültür çeşitliği gibi etkenler nedeniyle yabancıların ilgisini çekmiştir. Bu nedenle Türk dilinin tarihini, kültürünü ve önemini ortaya çıkarmak ve bunu ilgilenen kişilerle buluşturmak için çeşitli araştırma ve incelemelerde bulunulmuştur. $\mathrm{Bu}$ incelemelerin başında dil ve kültür araştırmaları yer almıştır. Bu dil ve kültür araştırmalarını inceleyen kollardan biri de ağız araştırmalarıdır.

Bir üst paragraftan hareketle Türkiye Türkçesinin ağızlarına ilk ilgi yabancı araştırmacılar tarafından, 1940'lı yıllardan sonra da yerli araştırmacılar tarafından gerçekleşmiştir (Korkmaz, 2017: 1161). Yerli araştırmacıların bu sahaya dâhil olmasıyla ağız araştırmalarının hızı artmış ve ağızlarla ilgili pek çok derleme, inceleme, karşılaştırma çalışmaları yapılmıştır. Bu çalışmalar neticesinde de Türk diline ilişkin bilgi ve malzemeler gün yüzüne çıkarılmıştır.

${ }^{1}$ Ayrıntılı bilgi için bk. Abdizâde Hüseyin Hüsameddin Efendi (1927). Amasya Tarihi, C. 4, İstanbul, Necm-i İstikbal Matbaası, s. 384 -390. Kurşun, Zekeriya vd., (1999) Evliya Çelebi Seyahatnâmesi, C. 2, İstanbul, Yapı Kredi Yayınları, s. 202-205. 
Ağız terimi "bir dilin (langue) veya lehçesinin (dialecte) sınırları içinde belli bölge veya topluluklara özgü sözlü anlatım yollarının bütünü"dür (Gemalmaz, 2010: 331), "Bir dilin bir şive içinde mevcut olan ve söyleyiş farklarına dayanan küçük kollara, bir memleketin çeşitli bölge ve şehirlerinin kelimeleri söyleyiş bakımından birbirinden ayrı olan konuşmalarına verdiğimiz addır" (Ergin, 2002: 10), "bir dilin veya bir lehçenin yazı diline oranla ve çoğunlukla ses, bazen de şekil, anlam ve söz varlığı bakımından birbirinden az çok ayrılan konuşma biçimleri”dir (Korkmaz, 2007: 11-12) şeklinde tanımlanmıştır.

Türkiye Türkçesi ağızları, gerek ses bilgisi ve şekil bilgisiyle gerekse de söz varlığı açısından dilimizin en önemli parçalarından biridir. Ses, şekil ve kelime/söz varlığı bakımından Oğuz Türkçesine dayanan Türkiye Türkçesi ağızlarında arkaik "eskicil” izleri görmek mümkündür. Bu nedenle Türkiye Türkçesi ağızlarındaki ses, şekil ve kelimelerdeki anlam eşitliklerine başvururken çoğunlukla arkaik/eskicil özelliklerden yararlanılmaktadır.

Arkaik/eskicil terimi Türkçe Sözlük’te "konuşulan ve yazılan dilde kullanımdan düşmüş olan eski söz veya deyim" dir $^{2}$ olarak tanımlanmıştır. Arkaik/eskicil terimi farklı araştırmacılar tarafında ise şu şekilde tanımlanmıştır: Ölmez, "Türk dilindeki ses ve şekil özellikleriyle sözlüksel biçimlerin Eski Türkçeyle karşılaştırıldığında diğer Türk lehçe ve şivelerinde bulunmaması ve Eski Türkçeye benzer biçimde bu ağızda yaşamasıdır (Ölmez, 2003: 136). Korkmaz, eskilik başlığı altında "eskiden kalma; yazı ve konuşma dilinde artık kullanıştan düşmüş olan, dilin daha eski veya tarihî devrelerine ait kelime, deyim ve şekiller" (Korkmaz, 2007: 55), Vardar, "eskil biçim", "eskilik" başlığı altında kullanımdan düşmüş bulunan sözlüksel birim, söz dizimsel olgu (Vardar, 2002, s. 93) biçiminde tanımlanmıştır.

$\mathrm{Bu}$ çalışmada Türkiye Türkçesi Ağızları içeresinde yer alan Ladik (Samsun) ağzının arkaik/eskicil unsurları ele alınmış ve gerekli yerlerde de Türk lehçelerine değinilerek açıklamalarda bulunulmaya çalış1lmıştır.

Ladik (Samsun) ağzında tespit edilen kelimelerin arkaik/eskicil unsurları Eski Türkçeden başlanarak tarihî seyirleriyle verilmiştir. Arkaik unsurlar verilirken S. G. Clauson'un etimolojik sözlüğü An Etymological Dictionary of Pre-Thirteenth Century Turkish (EDPT), Talat Tekin'in Orhon Yazıtları (OY), A. Von Gabain'in Eski Türkçenin Grameri (ETG), Ahmet Caferoğlu'nun Eski Uygur Türkçesi Sözlüğü (EUTS), Karahanlı Türkçesi döneminin başlıca eserleri olan Kutadgu Bilig (KB) ve Divanü Lügati't-Türk (DLT), Aysu Ata tarafindan dizini yapılan Nehcü'l Frād Ts III DizinSözlük (NFD-S), Recep Toparlı vd.'nin Kipçak Türkçesi Sözlüğü (KTS), Erol Öztürk'ün Eski Anadolu Türkçesi El Kitabı (EATEK) ve Cem Dilçin'in Yeni Tarama Sözlüğü (YTS)'deki şekilleriyle verilmiştir.

a-::" (<ăg-) EDPT'de ăg-“Yükselmek, yukarı çıkmak, kalkmak” (Clauson, 1972: 77); ag“yükselmek, çıkmak" (Tekin, 2010: 119); ETG'de ag- "binmek, çıkmak" (Gabain, 2007: 259); EUTS'de $a \dot{g} m a \perp$ “yükselmek, ağmak, kalkmak, yukarı çıkmak” (Caferoğlu, 1968: 7); KB'de ag“yükselmek, çıkmak" (Arat, 2008: 1095); DLT'de agmak "çıkmak, belirmek; aşmak, yükselmek, ağmak; değişmek, başkalaşmak, bozulmak, meyletmek, dönmek" (Atalay, 1986: IV-9) āg- ag-

\footnotetext{
${ }^{2}$ https://sozluk.gov.tr/?fbclid=IwAR378pkol95AjKr-y0X0XkbqTLulBQBd7Ek4szagzEM-ybzO_vmq0MQcCdU 10.04.2020/11.45

${ }^{3}$ Parantez işareti içesinde yararlanılan eserlerin kısaltması verilmiştir. İncelemelerde eser adının tekrarını yapmamak için kısaltmalar kullanılmıştır.

${ }^{4}$ Ladik (Samsun) ağzında “yükselmek (mec.) diklenmek, karşı gelmek” anlamında kullanılmıştır. Bir kelimede avcaġayá “Ağcakaya (Ladik'e bağlı yer adı)" şeklinde de kullanımı mevcuttur. Bu ise Kıpçakçada sıklıkla görülen g $>$ v değişiminin yöre ağzında etkisinin devam ettirmesinden kaynaklanır. Bk. Mustafa Öner (1998). Bugünkü Kıpçak Türkçesi, Ankara, Türk Dil Kurumu Yayınları, s.14-15; Leyla Karahan (1996) Anadolu Ağızlarının Sinıflandırllması, Ankara, Türk Dil Kurumu Yayınları, s. 115; Necati Demir (2000). "Karadeniz Bölgesi Ağızlarında Kıpçak Türkçesi Özellikleri”. IV. Uluslararası Türk Dili Kurultayı Bildirileri-I (24 Eylül-29 Eylül 2000) Ankara, 2007, s. 420. Ayrıca bu ses değişimi haricinde Kıpçakçada görülen diğer ses değişimlerinin de Ladik (Samsun) ağzında kullanımı mevcuttur.
} 
“yükselmek, çıkmak" (Ercilasun ve Akkoyunlu, 2015: 542); EATEK'de ag- "yükselmek" (Öztürk, 2017: 274); YTS'de ag்ma $\perp$ "1 Çıkmak, yükselmek. 2 Aşağı inmek, ağır gelip aşağı meyletmek." (Dilçin, 1983: 4).

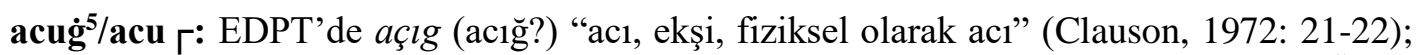
ETG'de açı ' "acı, hiddet, kuvvetli, pek" "hediye" (Gabain, 2007: 258); EUTS'de açıg "1. Öfke, kızma şiddet. 2. Acı ızdırap. 3. Ekşi acımtırak. 4. Hediye, armağan= Moğ. açuğ, açağ” (Caferoğlu, 1968: 2); KB'de açı ' “acı" (Arat, 2008: 1093); DLT'de açı̆̆ “acı, acı olan her nesne; ekşi”" (Atalay, 1986: IV-) açıg "ekşi, acı, nimetlenme" (Ercilasun ve Akkoyunlu, 2015: 538); NFD-S'de açıg "acı; ac1, 1ztırap, elem" (Ata, 1998: 4).

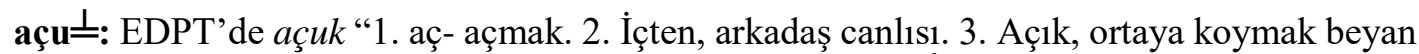

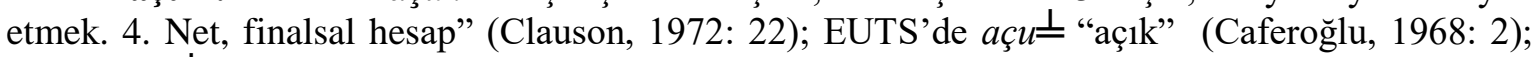

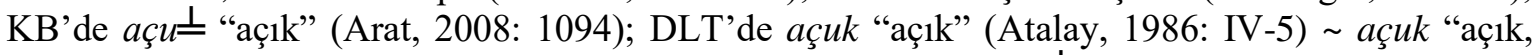
açılmış; net" (Ercilasun ve Akkoyunlu, 2015: 538); NFD-S'de açu^ "açık, kapalı olmayan" (Ata,

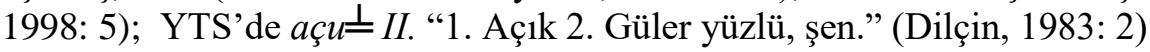

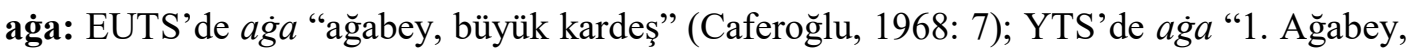
büyük oğul, büyük erkek kardeş. 2. Baba, ata. 3. Efendi, büyük, amir.” (Dilçin, 1983: 2).

alıtun: EDPT' de altun "altın” (Clauson, 1972: 78); OY'de altun “altın” (Tekin, 2010: 121); ETG'de altun, altum "altın" (Gabain, 2007: 260); EUTS'de altun "1. Altın 2. Zühre y1ldızının ad1, sabah (Akşam) yıldızının adı." (Caferoğlu, 1968: 13); KB'de altun "altın" (Arat, 2008: 1098); DLT'de altun "altın" (Atalay, 1986: IV-22) altun "altın, dinar" (Ercilasun ve Akkoyunlu, 2015: 549); YTS'de altun "altın" (Dilçin, 1983:8).

ārı: EDPT'de arı̆̆ “ temiz, saf, has” (Clauson, 1972: 78); ETG'de arig “arı, temiz, saf, mukaddes" (2007: 261); EUTS'de “temiz, arı, saf, kusursuz, mukaddes" (Caferoğlu, 1968: 19); KB'de arıg “temiz, pak" (Arat, 2008: 1099); DLT'de arı̆g “temiz" (Atalay, 1986: IV-32) arig arīg "temiz" (Ercilasun ve Akkoyunlu, 2015: 549); NFD-S'de arig "arı, pak, temiz; günahsı" (Ata, 1998:

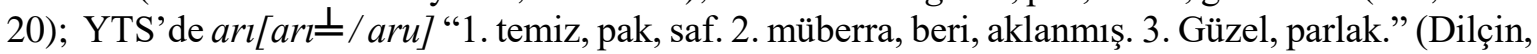
1983: 12).

artug / artu Г: EDPT'de (artok?) artuk "fazla, çok" (Clauson, 1972: 204); OY'de artu」

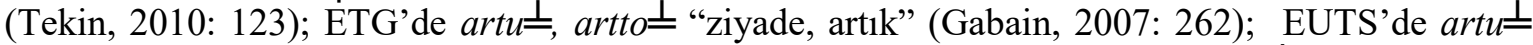
"artık, çok, fazla, arta kalan, son, son derece" (Caferoğlu, 1968: 23); KB'de artu^ "fazla, ziyade, daha çok" (Arat, 2008: 1100); DLT'de artuk "fazla, ziyade" (Atalay, 1986: IV-39) artuk "fazla, fazlalık" (Ercilasun ve Akkoyunlu, 2015: 558); NFD-S'de artu $\perp$ "fazla, çok; değerli, kıymetli" (Ata,

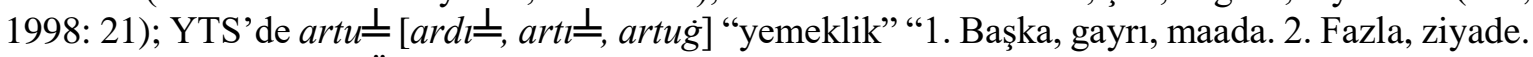
3. Küsür, -den fazla. 4. Üstün 5. Bir bütünün büyük bir kısmı.” (Dilçin, 1983: 14).

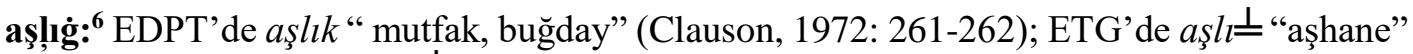
(Gabain, 2007: 262); EUTS' de $a s ̧ l ı$ " "mutfak" (Caferoğlu, 1968: 21); DLT'de aşlık "aş evi, mutfak; yemeklik; (oğuzlarca) buğday" (Atalay, 1986: IV-43) aşlık "mutfak" āşlık aşlık 'Oğuzlarda buğday' (Ercilasun ve Akkoyunlu, 2015: 560); YTS'de aşlı „ “yemeklik” (Dilçin, 1983: 15).

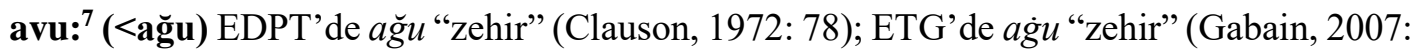
259); EUTS'de $a \dot{g} u$ "Ağ , zehir" (Caferoğlu, 1968: 8); ag் "ağı, zehir" (Arat, 2008: 1094); DLT'de agu "ağ1, zehir" (Atalay, 1986: IV-13) agu "zehir" (Ercilasun ve Akkoyunlu, 2015: 545); NFDS'de ag் "zehir, ağu" (Ata, 1998: 8).

\footnotetext{
${ }^{5}$ Ladik (Samsun) ağzında ekşi, mayhoş anlamındadır.

${ }^{6}$ Ladik (Samsun) ağzında buğday anlamındadır.

${ }^{7}$ Kıpçakçadaki $\dot{\mathrm{g}}>\mathrm{V}$ değişimi bu kelimede de etkisini göstermiştir.
} 
ayru: EDPT'de a $\pi^{1 r-} ; a_{\pi} r l \sim a y r u$ "ayrılmış, ayrılmış nesne", "başka" (Clauson, 1972: 63-

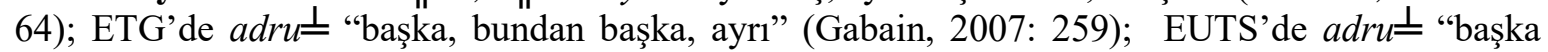
başka, eyrı, çeşitli, ayrı ayrı, çeşitli türden" (Caferoğlu, 1968: 5); DLT'de ayru "başka" (Atalay, 1986: IV-55) ayrı "değilse, başka" (Ercilasun ve Akkoyunlu, 2015: 560); EATEK'de ayru "ayrı, farkl1, başka" (Öztürk, 2017: 106); YTS'de ayru "başka, öteki, diğer" (Dilçin, 1983: 20).

az-: EDPT'de $a z$ - "kötü yola sapmak, yolunu kaybetmek, baştan çıkmak" "bozulmak, kötüye gitmek" (Clauson, 1972: 279); EUTS'de azag başlığında "yanlış yola sapmış" (Caferoğlu, 1968: 28) KB'de $a z$ - "azmak, yolu şaşırmak, yoldan çıkmak" (Arat, 2008: 1108); DLT'de $a z-$ "yoldan çıkmak" (Atalay, 1986: IV-56) az- "(yol için) şaşırmak, kaybetmek" (Ercilasun ve Akkoyunlu, 2015: 567); NFD-S'de az- "azmak, doğru yoldan çıkmak" (Ata, 1998: 39); YTS'de $a z m a \perp$ (II) "1. Bozulmak, değişmek. 2. Yolunu şaşırmak. 3. Sapkınlığa düşmek. 4. Azgınlaşmak. 5. Ayrı düşmek, ayrılmak.” (Dilçin, 1983: 21).

āzzı̇̀: EDPT'de azuk azuğ/azuk azık "yol yiyeceği, yiyecek" (Clauson, 1972: 283); OY'de azuk "azık, yiyecek" (Tekin, 2010: 125); EUTS'de azag başlığında "yanlış yola sapmış"

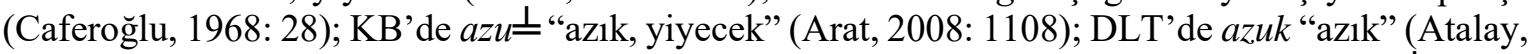

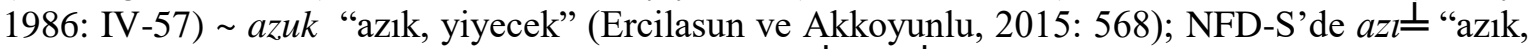
yol yiyeceği, yiyecek" (Ata, 1998: 21); YTS'de $a z u \stackrel{\perp}{\perp}[a z l \stackrel{\perp}{\perp} a z u \dot{g}]$ "yiyecek, yol yiyeceği, erzak" (Dilçin, 1983: 21).

batur-: EDPT'de batur- "batmasına sebep olmak, yol açmak", "batırmak" (Clauson, 1972: 308); ETG'de batur- "gizlemek" (Gabain, 2007: 267); EUTS'de baturma $\perp$ "gizlemek, saklamak" (Caferoğlu, 1968: 36); KB'de batur- "batırmak" (Arat, 2008: 1113); DLT'de batur- "saklamak; batırmak; bağlatmak" (Atalay, 1986: IV-76) batur- "(birini veya bir şeyi su vb. şeylere) batırmak" (Ercilasun ve Akkoyunlu, 2015: 579); YTS'de baturma $\perp$ "batırmak" (Dilçin, 1983: 28).

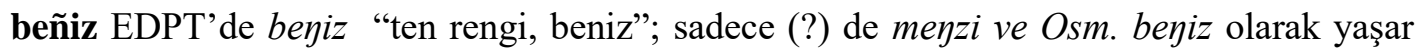
(Clauson, 1972: 352); ETG'de mäyiz, mänís "görünüş, güzellik" (Gabain, 2007: 286); EUTS'de mängiz "beniz, görünüş" (Caferoğlu, 1968: 129); KB’de me $\square i z$ "beniz, yüz" (Arat, 2008: 1199); DLT'de menğ(i)z "beniz, yüz" (Atalay, 1986: IV-411) meyiz "insanın rengi, beniz" (Ercilasun ve Akkoyunlu, 2015: 767); YTS’de beniz “1. Renk. 2. Yüz.” (Dilçin, 1983: 30).

berü: EDPT'de berü “bu tarafa" (Clauson, 1972: 355-353); EUTS'de bärü "beri, beriye" (Caferoğlu, 1968: 40); KB'de berü "beri" (Arat, 2008: 1117); DLT'de berï "beri, tarafina" (Atalay, 1986: IV-85) berü "beri, konuşana doğru" (Ercilasun ve Akkoyunlu, 2015: 583); NFD-S'de berü "beri” (Ata, 1998: 59); EATEK'de berï "içe doğru, içeriye" (Öztürk, 2017: 107); YTS'de berü [beri] "bu yana, buraya, beriye" (Dilçin, 1983: 39, 157).

bıldır: EDPT'de bıldır "geçen y1l" (Clauson, 1972: 334); DLT'de bıldır "bıldır, geçen yıl"” (Atalay, 1986: IV-89) bıldır "geçen yıl" (Ercilasun ve Akkoyunlu, 2015: 585); NFD-S'de bildır "geçen yıl”" (Ata, 1998: 60); YTS'de bildır, [buldur] "geçen yll" (Dilçin, 1983: 32).

biş-/bişür-: EDPT'de bış-, Çağ, Kıp biş-; Osm. biş- (piş-) "olgunlaşmak, pişmek, yemek pişirmek" (Clauson, 1972: 376-377) ETG'de bışs, biş- "olmak, pişmek" (Gabain, 2007: 286); EUTS'de bışma $\perp$ "olgunlşmak, öğrenmek, pişmek, pişkin hâle gelmek"; bışurma $\perp$ "pişirmek" (Caferoğlu, 1968: 41); KB'de bış- "pişmek, olgunlaşmak"; pışur- "pişirmek" (Arat, 2008: 1117); DLT’de pış- "pişmek, olmak, kımız tulumunu olması için saklamak"; pışur- "pişirmek" (Atalay, 1986: IV-473-474) blş- "yemek pişmek"; bışur- "pişirmek" (Ercilasun ve Akkoyunlu, 2015: 585586); NFD-S'de bışur-, bişür- " pişirmek" (Ata, 1998: 61); EATEK'de piş- "ateşte, firında ya da kaynayan suda pişmek" (Öztürk, 2017: 123); YTS'de bişmek "pişirmek"; bişürmek, [bişirmek] "1. Pişirmek. 2. Olgunlaştırmak. 3. Beslemek, geliştirmek" (Dilçin, 1983: 35).

boḷ-: EDPT' de bol- "olmak" (Clauson, 1972: 331); OY'de bol- "olmak" (Tekin, 2010: 133); EUTS'de bolma $\perp$ “olmak" (Caferoğlu, 1968: 47); KB'de bol- "olmak" (Arat, 2008: 1125); DLT'de 
bol- "olmak" (Atalay, 1986: IV-102) bol- "olmak, mevcut olmak" (Ercilasun ve Akkoyunlu, 2015: 593); NFD-S'de bol- “olmak” (Ata, 1998: 74); YTS'de bolma $\Perp$ “olmak” (Dilçin, 1983: 37).

börü: EDPT'de böri/börü “kurt” (Clauson, 1972: 356); ETG'de böri “kurt, börü” (Gabain, 2007: 269); EUTS'de böri "kurt, börü" (Caferoğlu, 1968: 50); KB'de böri "kurt" (Arat, 2008: 1128); DLT'de böri "kurt" (Atalay, 1986: IV-108) böri "kurt, börü" (Ercilasun ve Akkoyunlu, 2015: 598); NFD-S'de böri, börü "kurt" (Ata, 1998: 84).

çét: EDPT'de çit "ipek kumaş" (Clauson, 1972: 402); DLT'de çit "üzeri alaca nakışlı Çin ipeklisi” (Atalay, 1986: IV-154) çit “üzerine nakışlar basılmıș Çin ipeği” (Ercilasun ve Akkoyunlu, 2015: 625); YTS'de çit, [- bezi] "bir çeşit yerli kumaş, yazma yemeni, basma" (Dilçin, 1983: 57).

çetúK: EDPT'de çetük “kedi” (Clauson, 1972: 402); DLT'de çetük "kedi (Oğuzca)" (Atalay, 1986: IV-143) çetük "Oğuzcada kedi" (Ercilasun ve Akkoyunlu, 2015: 620); NFD-S'de çetük "kedi" (Ata, 1998: 101); YTS'de çetük, [cetük, çedük,çetik] "kedi” (Dilçin, 1983: 53).

çol̦aj̇/çoḷa Г: EDPT'de çoluk (çolok), Çağ. çolak "bir kolun eksik ya da sakat olması" (Clauson, 1972: 419); EUTS'de çulug "çolak, sakat" (Caferoğlu, 1968: 64); DLT'de çolak "çolak, sakat adam" (Atalay, 1986: IV-157) çoluk "çolak" (Ercilasun ve Akkoyunlu, 2015: 627).

delük: EDPT'de telük; Osm. delük, delik “delik" (Clauson, 1972: 498); DLT'de telik “delik" (Atalay, 1986: IV-596) telik "delik" (Ercilasun ve Akkoyunlu, 2015: 867); YTS'de delük "delik" (Dilçin, 1983: 63).

demür: EDPT'de temir/temür; Osm. demür "demir" (Clauson, 1972: 508); OY'de temir “demir (yer adında)" (Tekin, 2010: 173); ETG'de tämir "demir" (Gabain, 2007: 298); EUTS'de tämir "demir" (Caferoğlu, 1968: 233); KB'de temür "demir" (Arat, 2008: 1241); DLT'de temür "demir" (Atalay, 1986: IV-598) temür "demir" (Ercilasun ve Akkoyunlu, 2015: 868); NFD-S'de temür "demir" (Ata, 1998: 420); YTS'de demür, [timür] "demir" (Dilçin, 1983: 63).

de Liz: EDPT'de teniz Osm., Tkm. degiz "deniz, okyanus; derya" (Clauson, 1972: 527); KB'de tengiz "deniz" (Arat, 2008: 1241); DLT'de tenğiz "deniz" (Atalay, 1986: IV-599) tejiz "deniz" (Ercilasun ve Akkoyunlu, 2015: 841); EATEK'de de Liz "bahir, derya, deniz" (Öztürk, 2017: 109); YTS'de dejiz “deniz” (Dilçin, 1983: 64).

don: EDPT'de ton "giysi, elbise" (Clauson, 1972: 512); OY'de ton "elbise, giyim" (Tekin, 2010: 176); ETG'de ton, toon, tom "elbise, kürk" (Gabain, 2007: 301); EUTS'de ton "giyecek, elbise, don" (Caferoğlu, 1968: 246); KB'de ton "elbise, giysi" (Arat, 2008: 1250); DLT'de ton "elbise" (Atalay, 1986: IV-638) tōn ton "elbise" (Ercilasun ve Akkoyunlu, 2015: 841); NFDS'de ton "elbise" (Ata, 1998: 430); YTS'de ton, [don (I)] "1. Elbise, kılık kıyafet. 2. Renk" (Dilçin, 1983: 210).

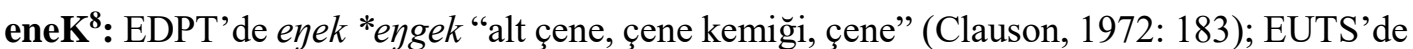
ängäk "çene kemiği, çene" (Caferoğlu, 1968: 72); DLT'de enğek "ağızın iki yanında; azıların bittiği yer, avurt; çene" (Atalay, 1986: IV-182); NFD-S'de engek "yanak" (Ata, 1998: 123); YTS'de ejek "1. Çene, çene kemiği. 2. gerdan" (Dilçin, 1983: 83)

enük: EDPT'de enük "genç saldırgan, etçil hayvan; yavru, enik; köpek yavrusu" (Clauson, 1972: 183); EUTS'de änük änüg "hayvan yavrusu" (Caferoğlu, 1968: 73); DLT'de enük "hayvan yavrusu, enik: arslan, sirtlan, kurt, köpek yavruları" (Atalay, 1986: IV-183) enük "aslan, sirtlan, kurt ve köpeğin yavrusu" (Ercilasun ve Akkoyunlu, 2015: 639); YTS'de enik, [enük] "et yiyen dört ayaklı hayvanların yavrusu, yavru" (Dilçin, 1983: 83).

\footnotetext{
${ }^{8}$ Kıpçak Türkçesinde $e \mathrm{~L}_{e g} \sim$ enek $\sim e \mathrm{~L}_{e k}$ "çene, çene kemiği” şeklindedir. Bk. Toparlı, R. vd. (2007). Kıpçak Türkçesi Sözlüğü, Ankara: Türk Dil Kurumu Yayınları, s. 73
} 
er: EDPT'de er "adam; erkek” (Clauson, 1972: 192); OY'de er “adam, erkek” (Tekin, 2010: 139); ETG'de är “er, bey” (Gabain, 2007: 264); EUTS'de är "erkek, kimse" (Caferoğlu, 1968: 73); KB'de er "er, erkek, adam" (Arat, 2008: 1144); DLT'de er "er, erkek, adam" (Atalay, 1986: IV-184) er "adam" (Ercilasun ve Akkoyunlu, 2015: 640); NFD-S'de er "kişi, koca, asker" (Ata, 1998: 124); EATEK'de er "koca, erkek, eş, insan, kul" (Öztürk, 2017: 111); YTS'de er "1. Koca, zevç. 2. Erkek, kişi. 3. Yiğit, kahraman. 4. Bektaşi şeyhi, mürşit, erenler. 5. Sahip.” (Dilçin, 1983: 83).

erüK/erüg: EDPT'de erük “genel olarak çekirdekli meyve" (Clauson, 1972: 222); EUTS'de ärük "erik" (Caferoğlu, 1968: 76); DLT'de erük "șeftali, kaysı, erik gibi meyvalara verilen genel ad" (Atalay, 1986: IV-193) erük "şeftali, kayısı, siyah erik türünün genel adı" (Ercilasun ve Akkoyunlu, 2015: 644).

èşit-: EDPT’de éşid- “işitmek” (Clauson, 1972: 257); OY’de eşid- "işitmek” (Tekin, 2010: 140); ETG'de äşit-; äşid-; işit-; işid-; esit- "işitmek" (Gabain, 2007: 265); EUTS'de äşidmäk äşitmäk "işitmek" (Caferoğlu, 1968: 77); KB'de eşit- "işitmek, duymak" (Arat, 2008: 1147); DLT'de éşit- "işitmek" (Atalay, 1986: IV-198) eşit- "işitmek, duymak" (Ercilasun ve Akkoyunlu, 2015: 647); NFD-S'de eş(i)t- "işitmek, duymak" (Ata, 1998: 137).

èyi/iyü: EDPT'de e đgü; Osm. eyü, iyi (éyü, éyi?) “iyi” (Clauson, 1972: 51); OY'de edgü “iyi; iyilik; kâr, kazanç, yarar" (Tekin, 2010: 137); ETG'de ädgü, ädhgü "iyi, iyilik, üstünlük" (Gabain, 2007: 263); EUTS'de ädgü “iyi, üstünlük" (Caferoğlu, 1968: 68); KB'de $e$ | gü “iyi” (Arat, 2008: 1139); DLT'de edhgü "iyi”" (Atalay, 1986: IV-168) eी gü "iyi” (Ercilasun ve Akkoyunlu, 2015: 632); NFD-S'de $e$ | gü “iyi”" (Ata, 1998: 113); YTS'de eyü, [eygü, eyi, iyü] “iyi” (Dilçin, 1983: $88)$.

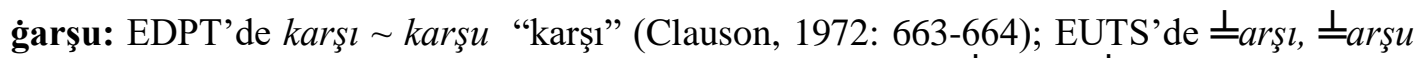

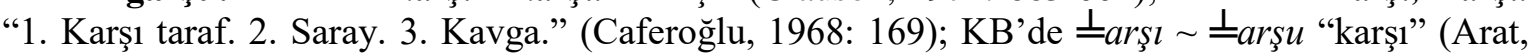
2008: 1168); DLT'de karşı karşu "karşı" (Atalay, 1986: IV-273-274) karşı "karşı" (Ercilasun ve

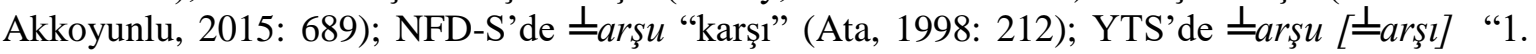
Karşılık olarak, mukabil. 2. Muhalif, ters iş. 3. Karşılığında, sırası gelince” (Dilçin, 1983: 128).

gart: EDPT’de kart “1. Yara. 2. Yaşlı" (Clauson, 1972: 647); EUTS’de ^ yara, çıbanl1. 2. Kart, ihtiyar" (Caferoğlu, 1968: 169); DLT'de kart "yara", kart er "huysuz adam" (Atalay, 1986: IV-274) kart "yara" kart er "huysuz adam" (Ercilasun ve Akkoyunlu, 2015: 689);

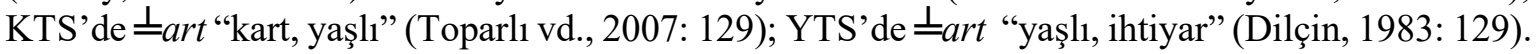

geçür-: EDPT'de keçür- "birinin veya bir şeyin karşıya geçmesi, (zaman) geçirmek” (Clauson, 1972: 698); EUTS'de käçürmäk, kiçürmäk "geçirmek" (Caferoğlu, 1968: 103); KB'de keçür- "geçirmek" (Arat, 2008: 1171); DLT'de keçür- "geçirmek" (Atalay, 1986: IV-291) keçür"geçirmek" (Ercilasun ve Akkoyunlu, 2015: 698); NFD-S'de keç(ü)r- "geçirmek; sürdürmek, devam ettirmek" (Ata, 1998: 212); YTS'de geçürmek "1. Vazgeçirmek, feragat ettirmek. 2. Geçiştirmek, affetmek, bağışlamak. 3. Saplamak, çakmak.” (Dilçin, 1983: 90).

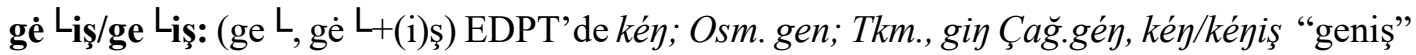
(Clauson, 1972: 724-725); ETG'de kiך "geniş, mufassal" (Gabain, 2007: 281); EUTS'de king "1. Tipk1, aynı, tam. 2. En, genişilik" (Caferoğlu, 1968: 110); KB'de ki $\square$ "geniş" (Arat, 2008: 1180); DLT'de king "geniş" (Atalay, 1986: IV-330) kiy "geniş" (Ercilasun ve Akkoyunlu, 2015: 720);

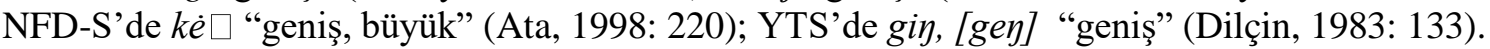

gèt-: EDPT’de két- "gitmek" (Clauson, 1972: 701); ETG’de kit- "gitmek" (Gabain, 2007: 265); EUTS'de kätmäk "gitmek, devam etmek" (Caferoğlu, 1968: 107); KB'de kit- "gitmek" (Arat, 2008: 1182); DLT'de kit- "gitmek" (Atalay, 1986: IV-336) kit- "gitmek" (Ercilasun ve Akkoyunlu, 2015: 724); NFD-S'de kèt- "gitmek; yok olmak" (Ata, 1998: 222); YTS'de gitmek "1. Yürümek, yürürlükte bulunmak. 2. Geçmek. 3. Kaybolmak.” (Dilçin, 1983: 93). 
gèy-: EDPT'de ke $\pi^{-;}$Kıp., Çă̆. key- Osm., Tkm. gey- "giymek" (Clauson, 1972: 700); ETG'de käd- "giymek" (Gabain, 2007: 279); EUTS'de käymäk "1. Karşı taraf. 2. Saray. 3. Kavga." (Caferoğlu, 1968: 169); KB'de ke - "giymek" (Arat, 2008: 1171); DLT'de kedh, ket- "giymek" (Atalay, 1986: IV-292, 307) ke - " "giymek” (Ercilasun ve Akkoyunlu, 2015: 699); NFD-S'de $k e_{\rceil}$, key- "giymek, giyinmek; kuşanmak" (Ata, 1998: 213); YTS'de geymek "1. Takınmak, takmak. 2. Kuşanmak. 3. Giymek, giyinmek" (Dilçin, 1983: 93).

goḷan: EDPT'de kolan "eyer kolanı" (Clauson, 1972: 622); DLT'de kolan kulan "kolan" (Atalay, 1986: IV-341) kolan "geçirmek" (Ercilasun ve Akkoyunlu, 2015: 726); KTS'de $\perp_{\text {olan }}$ "yular, eyer kolanı" (Toparlı vd., 2007: 152).

gonşı/ġoñşu: EDPT'de konşı “komşu” (Clauson, 1972: 640); ETG’de $\Perp_{\text {onşl, }} \perp_{\text {onaşı }}$

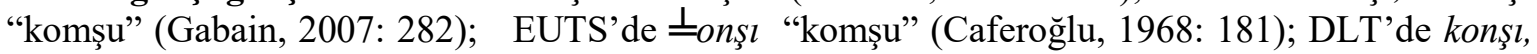
koşnı "komşu" (Atalay, 1986: IV-344, 348) konşı, koşnı "geçirmek" (Ercilasun ve Akkoyunlu,

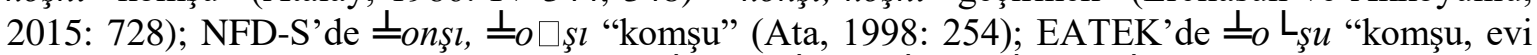

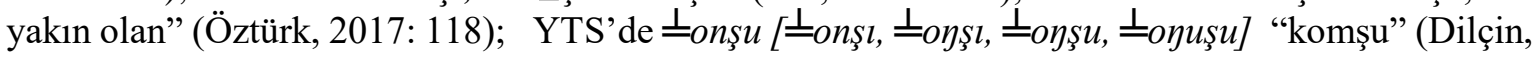
1983: 144).

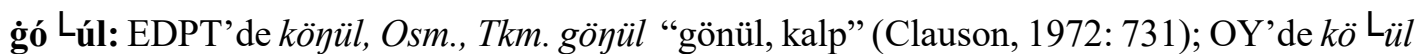
"gönüll” (Tekin, 2010: 154); ETG'de köyül "gönül” (Gabain, 2007: 283); EUTS'de kongül "gönül, kalp, fikir, istek, tefekkür, arzu ülkü” (Caferoğlu, 1968: 115); KB'de kö $\square \ddot{u l l ~ " g o ̈ n u ̈ l, ~ y u ̈ r e k ” ~(A r a t, ~}$ 2008: 1186); DLT'de könğül "gönül, kalp, yürek; anlayış" (Atalay, 1986: IV-361) köyül "kalp, gönül; zihin açıklığı ve idrak sürati” (Ercilasun ve Akkoyunlu, 2015: 788); NFD-S'de $k \ddot{o} \square(\ddot{u}) l$ "gönül, yürek; hafiza, akıl" (Ata, 1998: 259); EATEK'de gö L $\ddot{u l l ~ " i n s a n ~ h i s ~ v e ~ d u y g u l a r ı n ı n ~ m e r k e z i " ~}$ (Öztürk, 2017: 114); YTS’de göyül “1. Gönül. 2. Yürek.” (Dilçin, 1983: 97).

göynek: EDPT'de köylek, Kır. köynök; Kzx. Köylek; Uzb. kūylak/kŭynak; Nog. Köylek; Az., Tkm. köynek "gömlek" (Clauson, 1972: 732); KB'de kö $\square$ lek "gömlek" (Arat, 2008: 1186); DLT'de könğlek "gömlek" (Atalay, 1986: IV-361) könlek "gömlek" (Ercilasun ve Akkoyunlu, 2015: 738); NFD-S'de kö $\square l e k$ "gömlek, elbise" (Ata, 1998: 259); YTS'de göynek [göyünek] "1. Gömlek" (Dilçin, 1983: 99).

Ira Г: EDPT'de trak "uzak, uzakta " (Clauson, 1972: 214); OY'de trak "irak, uzak" (Tekin,

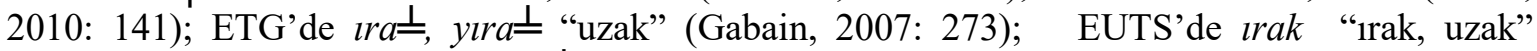
(Caferoğlu, 1968: 87); KB'de yıra $\perp$ "irak, uzak" (Arat, 2008: 1277); DLT'de yırak "uzak, rrak"

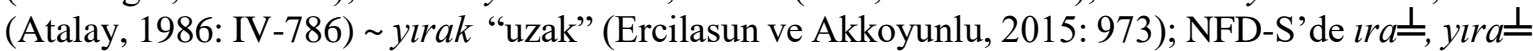
"uzak, rrak" (Ata, 1998: 178, 486); KTS'de $t r a-$, tra $\perp$, yıra $\perp$ “irak, uzak" (Toparlı vd., 2007: 101); YTS'de $t r a \stackrel{\perp}{\perp}$ [ragg, $\iota r a-, y ı r a \perp]$ "uzak" (Dilçin, 1983: 97).

Iran-/ırg்ın-: EDPT'de ırğan- "sallanmak, sarsılmak" (Clauson, 1972: 214); EUTS'de

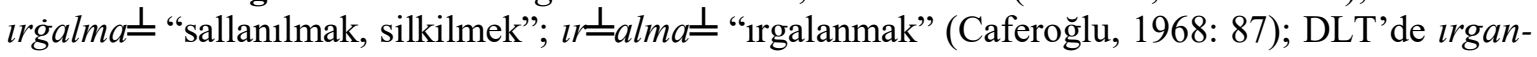
"irgalanmak" (Atalay, 1986: IV-218) trgan- "sarsilmak" (Ercilasun ve Akkoyunlu, 2015: 657);

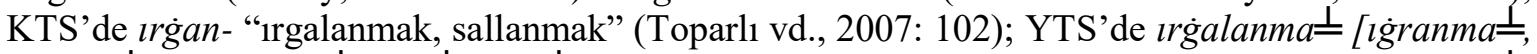

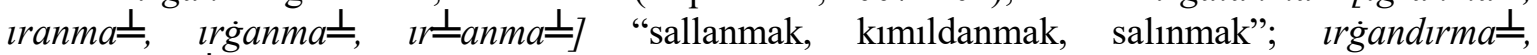

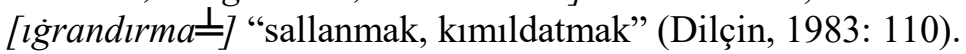

il': EDPT’de él "il, devlet; halk; hakan, hükümdar; barış, iki bey arasında barışıklık" (Clauson, 1972: 121-122); DLT'de él "İki bey arasında barışıklık" (Atalay, 1986: IV-176) ${ }^{l}$ "İki hakan arasındaki barış" (Ercilasun ve Akkoyunlu, 2015: 664); KTS'de Tl, el (IV) "sulh, barış" (Toparlı vd., 2007: 109); YTS'de il (I), [el] “1. Memleket, ülke, yurt, diyar, iklim, vilayet. 2. Halk,

\footnotetext{
${ }^{9}$ Ladik (Samsun) ağzında illig <il+lik birleşimiyle oluşmuş olan bu kelime anlam olarak "illik, dostluk, barışıklık" şeklindedir.
} 
ahali, kendisine yabancı olanlar, başkası. 3. Hısım, akraba, yabancı olmayan, dost. 4. Oba, aşiret.” (Dilçin, 1983: 110).

kece/gèce: EDPT'de kéçe (géce) "gece; dün" (Clauson, 1972: 694, 695); ETG’de kiçä "akşam, gece" (Gabain, 2007: 281); EUTS'de kiçä, käçä "gece, geceleyin” (Caferoğlu, 1968: 108109); KB'de kiçe "gece" (Arat, 2008: 1179); DLT'de kéçe "gece" (Atalay, 1986: IV-638) keçe, kiçe "gece" (Ercilasun ve Akkoyunlu, 2015: 697); NFD-S'de kéçe "gece, akşam" (Ata, 1998: 212); EATEK'de gice "gece, leyl, şeb, tün, günün karanlık kısmı" (Öztürk, 2017: 154); YTS'de gice "gece" (Dilçin, 1983: 93).

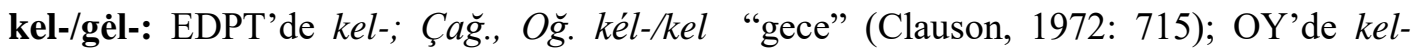

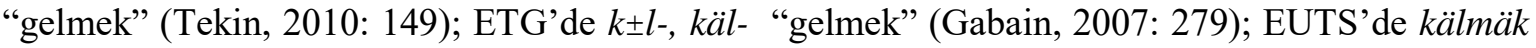
"gelmek" (Caferoğlu, 1968: 104); KB'de kel- "gelmek" (Arat, 2008: 1171); DLT'de kel- "gelmek" (Atalay, 1986: IV-295) kel- "gelmek" (Ercilasun ve Akkoyunlu, 2015: 700); NFD-S'de kel"gelmek; meydana gelmek, zahir olmak; dönmek, dönüşmek; uygun düşmek; münasip olmak" (Ata, 1998: 213); EATEK'de gel- "gelmek, inmek, geri dönmek" (Öztürk, 2017: 113); YTS'de gelmek "1. Naklonulmak, hikâye edilmek. 2. Geçmek, varit olmak.” (Dilçin, 1983: 91).

kendü/gendü: EDPT'de kentü; Xak., Kip. kendü; Osm. kendü, gendü "kendi" (Clauson, 1972: 728-729); OY'de kentü "kendi, öz; kendin" (Tekin, 2010: 149); ETG'de käntü, kändü "kendi” (Gabain, 2007: 279); EUTS'de käntü, kändï "kendi" (Caferoğlu, 1968: 105-106); KB'de kendü "kendi" (Arat, 2008: 1173); DLT'de kendü "kendi" (Atalay, 1986: IV-300) kendü, kendi "kendi" (Ercilasun ve Akkoyunlu, 2015: 703); NFD-S'de kendü "kendi" (Ata, 1998: 220); YTS'de kendü, [kendi] "kendi, kendisi" (Dilçin, 1983: 133).

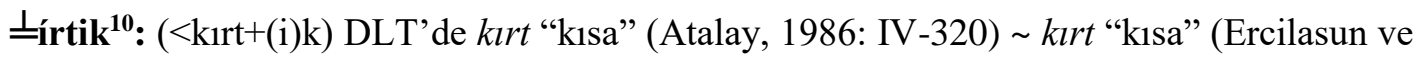
Akkoyunlu, 2015: 703).

上'ún11: EDPT'de kün; Osm, Tkm. gün "güneş; gün” (Clauson, 1972: 725); OY’de kün "gün; güneş" (Tekin, 2010: 156); ETG'de kün "gün, güneş” (Gabain, 2007: 158); EUTS'de kün "1. Güneş. 2. Gün. 3. Güney. 4. Zaman. 5. Lakaplarda kullanılır. 6. İl kün 'millet, kavim’ burada çoğul ekidir." (Caferoğlu, 1968: 122); KB'de kün "gün, gündüz" (Arat, 2008: 1195); DLT'de kün "gün, güneş, gündüz" (Atalay, 1986: IV-397) kün, kü̈n "gün; güneş" (Ercilasun ve Akkoyunlu, 2015: 756); NFD-S'de kün (1) "gün, gündüz"; kün (2) "güneş" (Ata, 1998: 271-272); YTS'de gün “1. Güneş. 2. Gündüz.” (Dilçin, 1983: 103).

men: EDPT'de men "ben" (Clauson, 1972: 346); OY'de men "ben, -im" (Tekin, 2010: 158); ETG'de män, mäm, min "ben" (Gabain, 2007: 286); EUTS'de män "ben (Zamir)" (Caferoğlu, 1968: 129); KB'de men, min "ben" (Arat, 2008: 1198); DLT'de men, ben (Ŏguz, Kıp., Suvarlar) "ben" (Atalay, 1986: IV-409) men, ben "ben" (Ercilasun ve Akkoyunlu, 2015: 762, 582); NFD-S'de men "ben" (Ata, 1998: 282); YTS'de [ben]; menlik "ben; benlik" (Dilçin, 1983: 30, 152).

mu'2: EDPT'de bu; bun- 'dan gelmiş olan bu kelime (çoğu dilde mun-)'dur. Anlam olarak "bu"dur. (Clauson, 1972: 291); EUTS'de mu "1. Soru edat1. 2. Bu." (Caferoğlu, 1968: 131-132); KB'de $m u$, bu "bu" (Arat, 2008: 11200); DLT'de bu "bu" (Atalay, 1986: IV-109) bu "bu" (Ercilasun ve Akkoyunlu, 2015: 762, 598); NFD-S'de $m u$, bu "bu" (Ata, 1998: 294); YTS'de [bu]; muna, munca muncılayın, munda "bu, buna, bunca, bu kadar burada" (Dilçin, 1983: 39, 154).

nece: EDPT'de neçe "ne kadar, kaç" (Clauson, 1972: 775); EUTS'de näçä "1. Ne kadar, kaç 2. Nasıl, herhangi" (Caferoğlu, 1968: 135); KB'de nece "nice, ne kadar, kaç, nasıl”" (Arat, 2008:

\footnotetext{
${ }^{10}$ Ladik (Samsun) ağzında "ufalanmış, incelmiş (sabun)" anlamında kullanılmıştır.

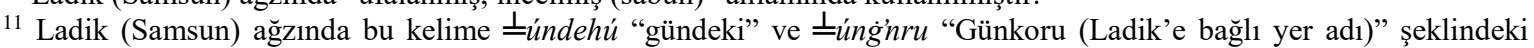
birleşik kelimede kullanılmıştır.

${ }^{12}$ Ladik (Samsun) ağzında munı, munnarı, munnara gibi çekimler de mevcuttur.
} 
1203); DLT'de nece (neçe) "ne kadar, nice, kaç" (Atalay, 1986: IV-419) nece "kaç, ne kadar" (Ercilasun ve Akkoyunlu, 2015: 768); NFD-S'de neçe "nice, ne kadar çok, ne kadar, pek çok, birçok, ne zaman" (Ata, 1998: 312); EATEK'de niçe "pek çok, o kadar" (Öztürk, 2017: 120); YTS'de nice, [niçe] "1. Nasıl. 2. Çok, birçok, hayli. 3. Çok kez. 4. Ne. 5. Ne zaman. 6. Kaç, ne kadar. 7. Hangi. 8. Ne kadar, ne derece. 9. Ne vakta kadar." (Dilçin, 1983: 39, 157).

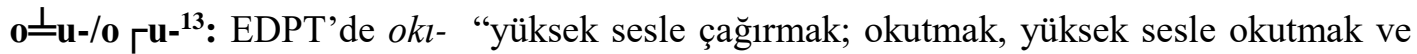
okumak"; davetçi anlamına gelen "oktţ̧ı" (Clauson, 1972: 79); OY'de okl- "çağırmak, davet etmek" (Tekin, 2010: 159); ETG'de $o_{l-}^{\perp}$, ohki "çağırmak, okumak" (Gabain, 2007: 288); EUTS'de ${ }^{\prime} \perp_{1 m a} \perp$ "1. Okumak. 2. Çağırmak, davet etmek."; okunç "çağrı, davet, çağırma"; okunçsuzın

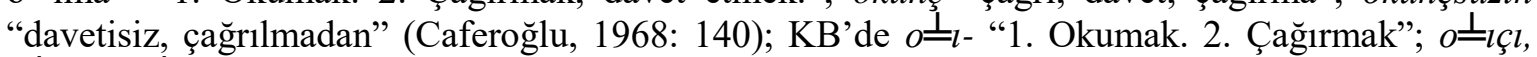

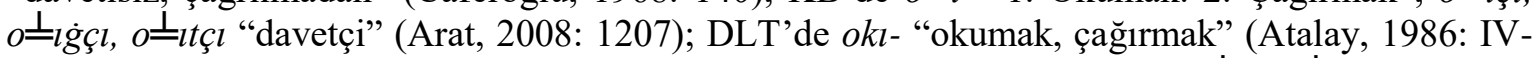
430) okl- "çağırmak" (Ercilasun ve Akkoyunlu, 2015: 772); EATEK'de $\rho_{l-} \iota_{l} \perp_{u-}$ " "yazıll bir belgeyi okumak, kıraat etmek" $o-l_{-}$"çağırmak" (Öztürk, 2017: 121, 209; 162); YTS'de okuyıcı/okucl "davetçi”" (Dilçin, 1983: 161).

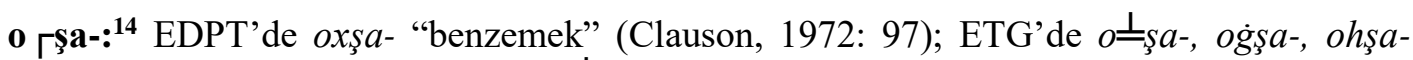

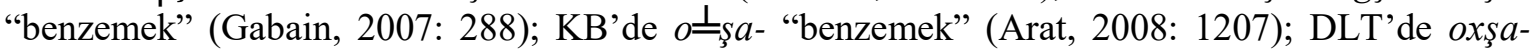
"okşamak, şakalaşmak, oynaşmak; benzemek" (Atalay, 1986: IV-428) oxşa- "benzemek"

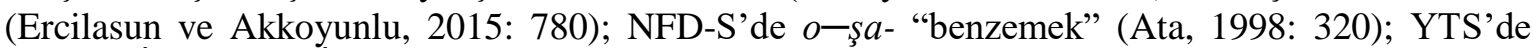

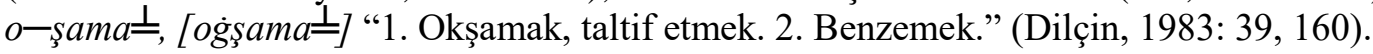

oḷ: EDPT'de ol "1. İşaret sıfatı, 2. İşaret zamiri (bu karşıtı), şahıs zamiri” (Clauson, 1972: 123); OY'de ol "o" (Tekin, 2010: 159); ETG'de ol "o" (Gabain, 2007: 288); EUTS'de ol "bu, o" (Caferoğlu, 1968: 141); KB'de ol "o; dir, dir, dur, dür" (Arat, 2008: 1203); DLT'de ol "o; dir, dir, dur, dür" (Atalay, 1986: IV-431) ol "o (3. Teklik kişi zamiri)" (Ercilasun ve Akkoyunlu, 2015: 773); NFD-S'de ol "o, (işaret sıfat1; zamir)" (Ata, 1998: 321); EATEK' de ol "o zamiri, işaret sıfatı" (Öztürk, 2017: 121); YTS'de ol "1. O, üçüncü tekil kişi adılı. 2. Öbür, öteki, diğer." (Dilçin, 1983: 39, 157).

ö L: EDPT'de ö “ön” (Clauson, 1972: 167); OY'de öyre "ileride, doğuda" (Tekin, 2010: 163); EUTS'de öng “1. Renk. 2. Ön taraf, önce, doğu. 3. Sahra, çöl." (Caferoğlu, 1968: 151); KB'de $\ddot{o} \square$ "ön” (Arat, 2008: 1217); DLT'de önğ "ön, önce; öndün (Oğuzca)" (Atalay, 1986: IV-459) ö "Oğuzlarda ön" (Ercilasun ve Akkoyunlu, 2015: 787); NFD-S'de $\ddot{o} \square$ "ön, ön taraf” (Ata, 1998: 329); YTS'de ö “1. Önce, mukaddem, evvel. 2. İleri, üstün, makbul.” (Dilçin, 1983: 39, 186).

övey/óvey ${ }^{15}$ : EDPT’de ögey "yalnızca bir ebeveyn aracılığıyla ilgili; (üvey baba)" (Clauson, 1972: 119); DLT'de ögey "üvey" (Atalay, 1986: IV-451) ögey (ata, klz, ogul) "üvey" (Ercilasun ve Akkoyunlu, 2015: 784); EATEK'de ögey “üvey, öz olmayan” (Öztürk, 2017: 162).

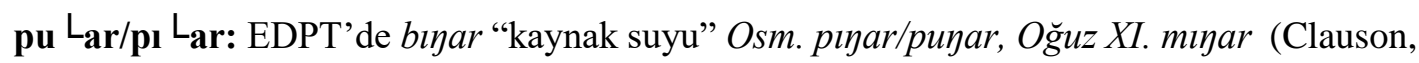
1972: 351); DLT'de mınğar "pınar, su gözü" (Atalay, 1986: IV-412) minar "su gözü, su gözesi”" (Ercilasun ve Akkoyunlu, 2015: 764); YTS'de bıłar, [büar] "pınar, çeşme" (Dilçin, 1983: 32).

sērt-16: (<sekirt-, segirt-) EDPT'de sékrit- "sıçratmak, atlatmak; hızlı koşmak" Klp., Osm. sekirt-, segirt- XIII., XV "ata binmek; (ordunun saldırmast için) ilerlemek, koşturmak" (Clauson, 1972: 822); KB'de sekirt- "seğirtmek, koşturmak" (Arat, 2008: 1228); DLT'de segirt-, sekirt-

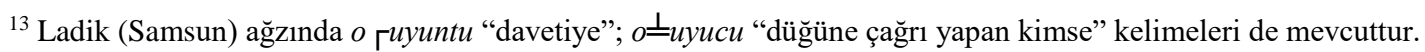
${ }^{1414}$ Ladik (Samsun) ağzında bu kelime $o \Gamma_{\zeta S ̧} a$ ç "benzer" şeklindedir. Kıpçak Türkçesinde o-şa- "benzemek, bir şeye uymak"; o-şaş; o-şaş-; o-şaşı ve o-şat- şekillerindedir. Bk. Toparlı (2007), s. 204.

${ }^{15}$ Türkmen Türkçesinde övey şeklindedir. Bk. Ercilasun, AB. vd. (1991). Karşılaştırmalı Türk Lehçeleri Sözlüğü I-II, Ankara: Kültür Bakanlığı Yayınları, s. 933.

${ }^{16}$ Ayrıca bu kelimenin $s^{*}$ F\|rt- "seğirtmek koşturmak"; sórtu gèl- "seğirterek gelmek, koşarak gelmek" şeklinde kullanımları da mevcuttur.
} 
"seğirtmek, koşturmak" (Atalay, 1986: IV-503) sekirt- "(at vb.ni) koşturmak" (Ercilasun ve Akkoyunlu, 2015: 816); NFD-S'de sekirt- "seğirtmek, hareket ettirmek, oynatmak" (Ata, 1998: 364); EATEK'de segird- "koşmak, seğirtmek" (Öztürk, 2017: 211); YTS'de segirtmek "1. Koşmak. 2. Yürümek. 3. Koşturmak. 4. Saldırmak, akın etmek, çapul için hücum etmek.” (Dilçin, 1983: 183).

sl- ${ }^{17}$ : EDPT'de $s l^{-}$"kırmak" (Clauson, 1972: 782); OY'de $s l^{-}$"kırmak" (Tekin, 2010: 165); ETG'de sl- "kırmak, yenmek" (Gabain, 2007: 293); EUTS'de slma $\perp$ "kırmak, sindırmak" (Caferoğlu, 1968: 203); KB'de sl- "kırmak, bozmak, ezmek, kırılmak" (Arat, 2008: 1228); DLT'de $s l$ - "kırmak; bozmak; yenmek, galebe etmek" (Atalay, 1986: IV-510) sī-, sl- "(odun, biçak vb. şeyleri) kırmak" (Ercilasun ve Akkoyunlu, 2015: 816); NFD-S'de sın-, sindur- "kırılmak; kırmak"

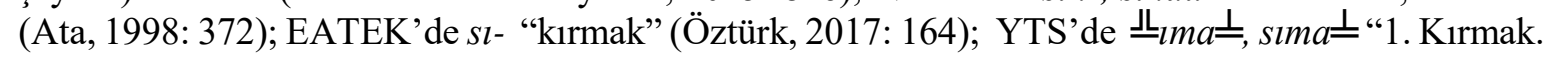
2. Bozmak, nakzetmek. 3. Yenmek, mağlup etmek, tepelemek. 4. Aşağı görmek. 5. Gereğini yapmamak, bertaraf etmek, reddetmek, hiçe saymak, kabul etmemek. 6. Yıkmak, harap etmek." (Dilçin, 1983: 39, 168).

sırı-: EDPT'de sırl- "yorgan, önlük dikmek" (Clauson, 1972: 845); DLT'de sırl- "pislemek, siymek; sık dikişle dikmek" (Atalay, 1986: IV-517) sırl- "sık dikişle dikmek" (Ercilasun ve

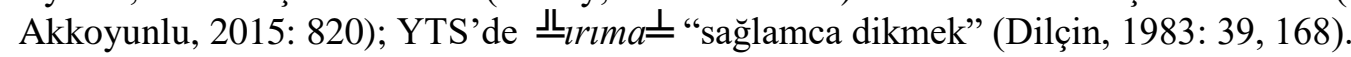

sin-/sí Lاl-: EDPT'de siy- "batmak; emmek; sindirmek; saklanmak" (Clauson, 1972: 833); DLT'de sinğ- "sinmek, hazmedilmek; işlemek, girmek; saklanmak, sahibine sormadan bir yere girip sinmek" (Atalay, 1986: IV-523) siy- "bir yere girip saklanmak" (Ercilasun ve Akkoyunlu, 2015: 820); KTS'de si L. "1. Sinmek, sokulmak, eğilmek. 2. Gizlenmek için yere yatmak." (Toparlı vd., 2007: 237); YTS'de sinmek "1. Hazmolunmak, vücuda mal olmak. 2. Nüfuz etmek, etkilemek, yerleşmek. 3. Hoşa gitmek, içine sinmek, yaramak. 4. Gizlenmek, saklanmak, yer tutmak.” (Dilçin, 1983: 39, 168).

sögüll-: EDPT'de sögül- “kızartmak; kebap yapmak” (Clauson, 1972: 821); ETG'de sögül"kıartılmak" (Gabain, 2007: 294); EUTS'de sögülmäk "kıartılmak" (Caferoğlu, 1968: 209); DLT'de sökül- "kızartılmak, kebap edilmek" (Atalay, 1986: IV-534) sögül- "(eti) 1zgara yapmak" (Ercilasun ve Akkoyunlu, 2015: 830); NFD-S'de sökül-, sökil- "kebap etmek" (Ata, 1998: 379); EATEK'de $s l^{-}$" "kırmak" (Öztürk, 2017: 164); YTS'de $\Perp_{l m a} \perp$, sıma $\perp$ "1. Kırmak. 2. Bozmak, nakzetmek. 3. Yenmek, mağlup etmek, tepelemek. 4. Aşağı görmek. 5. Gereğini yapmamak, bertaraf etmek, reddetmek, hiçe saymak, kabul etmemek. 6. Yıkmak, harap etmek." (Dilçin, 1983: 39, 168).

südük: EDPT'de $s i \pi \ddot{u} k$ “idrar, sidik" (Clauson, 1972: 801); ETG'de südük “idrar, sidik" (Gabain, 2007: 295); EUTS'de südük "sidik" (Caferoğlu, 1968: 214); DLT'de sidük, sidhük "sidik" (Atalay, 1986: IV-521) sidük, si引 $\ddot{\eta} k$ "her türlü idrar, sidik" (Ercilasun ve Akkoyunlu, 2015: 823); KTS'de sidik, sidük, sitük, siytük, südük "sidik, idrar" (Toparlı vd., 2007: 236); YTS'de [sidik] sidük, südük "idrar" (Dilçin, 1983: 39, 187).

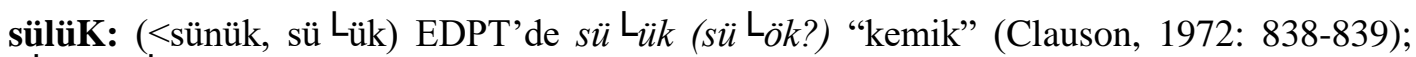

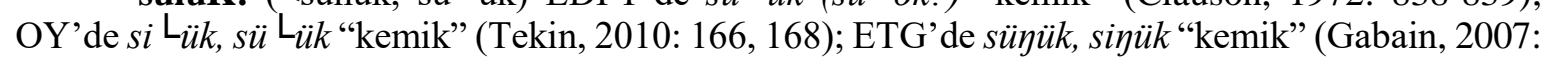
295); EUTS'de süngük “kemik" (Caferoğlu, 1968: 214); KB'de sü $\square \ddot{u ̈ k ~ “ k e m i k " ~(A r a t, ~ 2008: ~ 1234) ; ~}$ DLT'de sünğ̈̈k "kemik" (Atalay, 1986: IV-594) sü̈ük "kemik" (Ercilasun ve Akkoyunlu, 2015: 840); NFD-S'de sü $\square \ddot{u ̈ k ~ " k e m i k " ~(A t a, ~ 1998: ~ 384) ; ~ Y T S ' d e ~ s u ̈ \eta u ̈ k ~ " k e m i k " ~(D i l c ̧ i n, ~ 1983: ~ 39, ~ 196) . ~}$

ti-: EDPT'de té- (dé-) "söylemek" (Clauson, 1972: 433); OY'de ti- "demek, söylemek" (Tekin, 2010: 174); ETG'de ti-, te- "demek" (Gabain, 2007: 299); EUTS'de timäk "1. Demek, söylemek, dilemek. 2. Hazırlamak." (Caferoğlu, 1968: 239); KB'de ti- "demek” (Arat, 2008: 1243);

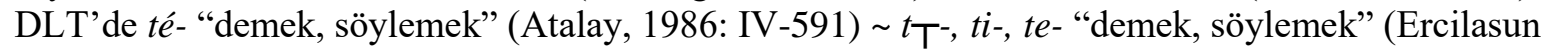

\footnotetext{
${ }^{17}$ Ladik ağzında sındar $\Omega$ èt- "kırmak, parçalamak" şeklinde kullanılmıştır.
} 
ve Akkoyunlu, 2015: 879); NFD-S'de te- "demek, söylemek" (Ata, 1998: 408); EATEK'de di"söylemek, demek" (Öztürk, 2017: 110); YTS'de [demek], [dimek] "demek” (Dilçin, 1983: 63, 68).

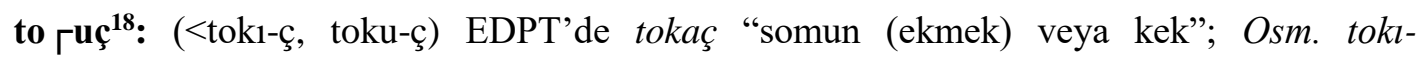
kelimesinin anlam değişikliğine uğramış şekli olarak tanımlanan bu kelime "tokmak; çamaşır yıkamada dövmek için kullanılan sopa" anlamındadır. (Clauson, 1972: 467); OY'de tokl- "vurmak, dövmek" (Tekin, 2010: 175); ETG'de $t o \perp_{l-,} t_{o} \perp_{u-}$ "vurmak, sokmak, kurma, kurmak, tepinmek;

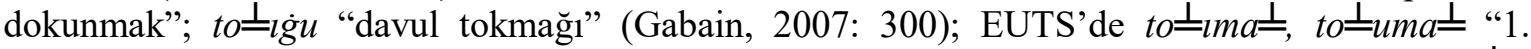
Dokumak. 2. Vurmak."; tokıga/u "tef, davul tokmağı" (Caferoğlu, 1968: 244-245); KB'de to $\perp_{l \text { - }}$ "dövmek, dokumak, vurmak, çalmak" (Arat, 2008: 1249); DLT'de tokl- "insan döğmek (Oğuzcada)" ur-, tokl- "demir döğmek; vurmak; çarpmak; dokumak; dokumak; götürmek ve batırmak"; tokımak "tokmak, çamaşır tokmağı"; tokuç "çörek" (Atalay, 1986: IV-633-635) tokl- " (madeni şeyleri) dövmek; dokumak; (akarsu) boğup götürmek; (cin) çarpmak"; tokaç "yuvarlak ve yass1 ekmek"; tokımak "çamaşırcı tokmağı" (Ercilasun ve Akkoyunlu, 2015: 888); NFD-S'de to $\perp_{u-,} \quad \perp_{l-} \perp_{l-}$

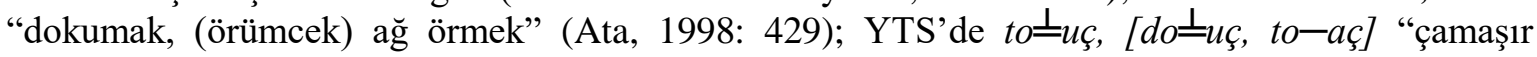
tokmağı, tokaç" (Dilçin, 1983: 209).

tol-: EDPT'de tol- "dolmak" (Clauson, 1972: 491); ETG'de tol- "dolmak, doldurmak" (Gabain, 2007: 301); KB'de tol- "dolmak" (Arat, 2008: 1249); DLT'de tol- "dolmak" (Atalay, 1986: IV-636) tol- "dolmak" (Ercilasun ve Akkoyunlu, 2015: 890); NFD-S'de tol- "dolmak" (Ata, 1998: 429); YTS'de [ $\boldsymbol{\square}_{\text {olma }} \perp$ ] "dolmak" (Dilçin, 1983: 209).

töre-: EDPT'de törü- (törö- $d$-?); Kom., Kıp. töre- Osm. dörü- “ ortaya çıkmak, yaratılmak” (Clauson, 1972: 533); OY'de töri- "yaratılmak" (Tekin, 2010: 177); ETG'de törü- "türemek, husule gelmek" (Gabain, 2007: 301); EUTS'de törütmäk "türetmek" (Caferoğlu, 1968: 250); KB'de töri-, törü- "yaratılmak, türemek; meydana gelmek" (Arat, 2008: 1251); DLT'de törü- "yaratılmak" (Atalay, 1986: IV-647) törü- "yaratılmak" (Ercilasun ve Akkoyunlu, 2015: 897); NFD-S'de törüt"yaratmak" (Ata, 1998: 432); EATEK'de içün "için" (Öztürk, 2017: 202); YTS'de türemek "peyda olmak" (Dilçin, 1983: 215).

uçun/üçün: EDPT'de üçün “ -den dolayı; uğruna, yoluna, amacına; için” (Clauson, 1972: 28); OY'de üçün "için, olduğundan" (Tekin, 2010: 182); ETG'de üçün, ücüm "için" (Gabain, 2007: 305); EUTS'de üçün "için, sebep, dolayısıyla" (Caferoğlu, 1968: 270); KB'de üçün "için" (Arat, 2008: 1264); DLT'de uçun "sebep bildiren bir edat; için" (Atalay, 1986: IV-682) üçün "sebep ifade eden bir edat, için" (Ercilasun ve Akkoyunlu, 2015: 929); NFD-S'de üçün "için" (Ata, 1998: 452); EATEK'de içün "için" (Öztürk, 2017: 202); YTS'de uç-ından, [-dan, ryla] "için, sebebiyle, sebepten, -den dolayı, yüzünden" (Dilçin, 1983: 216).

urun"19: (<oğr1+n) EDPT'de oğrl "hırsı"; oğrın "gizli, gizlice" (Clauson, 1972: 90); ETG'de og̀urla- "çalmak (hırsız)" (Gabain, 2007: 288); EUTS'de ogrrl "hırsız, haydut" (Caferoğlu, 1968: 139); KB'de ogrrl "hırsız, uğru"; ogrrn "gizlice" (Arat, 2008: 1206); DLT'de ogrt; urun "gizli"; ogrt "hırsız; hırsızlık" (Atalay, 1986: IV-425) ogrl "hırsız" (Ercilasun ve Akkoyunlu, 2015: 771); NFDS'de ogrl "hırsız" (Ata, 1998: 318); EATEK'de ogrrl "hırsız" (Öztürk, 2017: 121); KTS'de ogrrl,

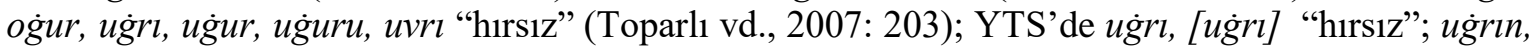

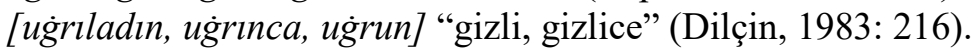

üt- ${ }^{20}$ : (<ut-) EDPT'de ut- Osm. ut-, üt- “1. Kumarda (bir şeyi) kazanmak'; 2. 'dövmek, yenmek (birini, çeşitli durumlarda); a) kumarda; b) savaşta vs." (Clauson, 1972: 38-39); ETG'de ut-

\footnotetext{
${ }^{18}$ Ladik (Samsun) ağzında bu kelime anlam olarak "tokaç, çamaşır yıkarken çamaşır dövmeye yarayan ağaç tokmak" demektir.

${ }^{19}$ Ladik (Samsun) ağzında bu kelime anlam olarak "gizli, gizlice" demektir.

${ }^{20}$ Ladik (Samsun) ağzında bu kelime "1. Taze buğday veya mısırı ateşe tutup pişirmek. 2. Oyunda yenmek" anlamlarında kullanılmıştır.
} 
"yenmek, utmak, ütmek" (Gabain, 2007: 305); EUTS'de utma $\Perp$ "1. Utmak, yenmek, kazanmak, galebe çalmak. 2. Takip etmek, ardını bırakmamak, birisinin arkasına gitmek" (Caferoğlu, 1968: 268); KB'de ut- "yenmek" (Arat, 2008: 1263); DLT'de ut- "oyunda yutmak, oyunda ütmek" (Atalay, 1986: IV-701) ut- "yenmek, galip gelmek" (Ercilasun ve Akkoyunlu, 2015: 925); YTS'de utma $\perp$, [ütmek (II), yutma $\perp$ (I)] “1. Yenmek, oyunda kazanmak. 2. Yararlanmak." (Dilçin, 1983: 221).

yálı Luz/yálu Luz: EDPT’de yalyus “tek başına, bir tek, sadece, yalnız” XI yüzyıl öncesi “-

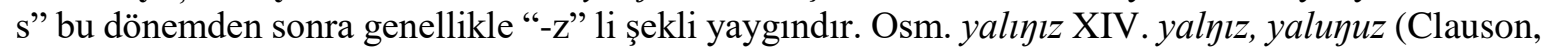
1972: 930-931); ETG'de yalayuz, yālińus, yālińuz "yalnız" (Gabain, 2007: 308); EUTS'de yalangus, yalanguz yalanguz "yalnız" (Caferoğlu, 1968: 281); KB'de yal $\square u z$ "yalnız" (Arat, 2008: 1269); DLT'de yalnğus "yalnız, kimsesiz" (Atalay, 1986: IV-736) yalnus "yalnız, tek başına" (Ercilasun

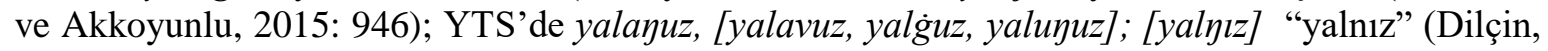
1983: 231-232).

yár: EDPT'de yar (2) “uçurum, yarık” Uy̆̆. "kaya tuzu” Osm. "aşınmış, yarılmış nehir yatağı" (Clauson, 1972: 953-954); DLT'de yar "yar, suların açtığı uçurum" (Atalay, 1986: IV-747) $\sim$ yār "yar, uçurum, sel sularının açtığı yarı"” (Ercilasun ve Akkoyunlu, 2015: 952); YTS'de yar (I) “yarılmış yer, suyun açtığı uçurum” (Dilçin, 1983: 235).

yáy-21: EDPT'de yay- "1. Çalkalamak, sallamak. 2. Yaymak, çırpmak” (Clauson, 1972:

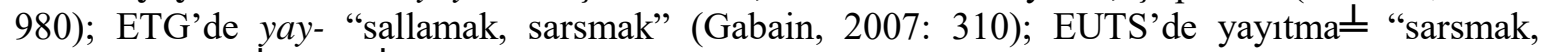
titretmek"; yay $\stackrel{\perp}{\text { alama }} \stackrel{\perp}{\perp}$ "sallanmak, yalpa vurmak, tereddüt göstermek" (Caferoğlu, 1968: 291); DLT'de yay- "çalkalamak, kımıldatmak, sallmak, meyletmeki meylettirmek" (Atalay, 1986: IV-763) yay- "oynatmak, sallamak; (elbise vb. şeyleri suda) çalkalamak" (Ercilasun ve Akkoyunlu, 2015: 961); YTS'de yayma $\perp$ "Yağını çıkarmak için yoğurdu yayıkta çalkalamak. 2. Tahrik etmek dağıtmak, perişan etmek" (Dilçin, 1983: 221).

yáy ran-22: (<yayka-, yaykal-, yaykan-) EDPT'de yayka- “yayuk'tan türeyen bu fiil, orta dönemden önce kaydedilmemiş fakat yaykal-/yaykan- olarak görülür. Genellikle 'sallamak' anlamıyla yaşıyor, özellikle "başı sallamak"; Osm. ise yıka- orijinalinde "çalkalamak" genel anlam olarak ise "yıkamak" (Clauson, 1972: 981); ETG'de yay $\Perp_{a l-}$ "sarsilmak"; yay $\Perp_{a n-}$ "sallanmak"

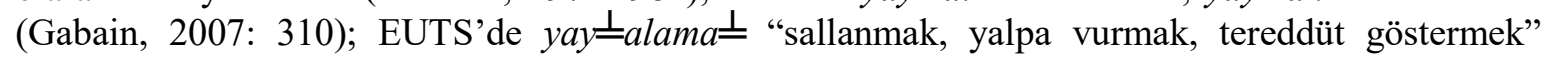
(Caferoğlu, 1968: 291); DLT'de yaykal- "çalkanmak; her şeye gönlü meyil göstermek" (Atalay, 1986: IV-764) yaykal- "(su vb..) çalkalanmak" (Ercilasun ve Akkoyunlu, 2015: 962); KTS'de yay $\perp_{a-}$ "(I) Ağız çalkalamak, çalkalayarak ağZı yıkamak (II) y1kamak"; yaykan- "çalkalanmak"

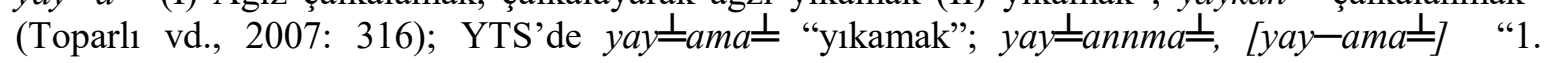
Yıkanmak. 2. Çalkalanmak, kımıldamak” (Dilçin, 1983: 240).

yáz-: EDPT’de yał- “yaymak (yere, zemine)” (Clauson, 1972: 923); ETG'de yad-

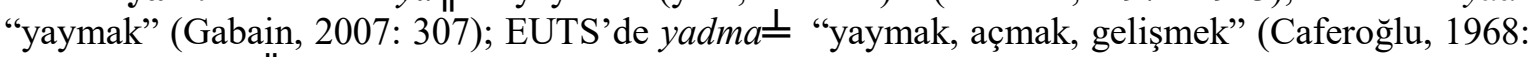
279); KB'de yał-, yay- "yaymak" (Arat, 2008: 1267, 1274); DLT'de yokar, yadh- "döşemek, yaymak, sermek" (Atalay, 1986: IV-724) ya -, yat- "yaymak, sermek" (Ercilasun ve Akkoyunlu, 2015: 939); NFD-S'de yay- "yaymak, dağıtmak, sermek, açmak" (Ata, 1998: 476); EATEK'de yaz"kalemle yazı yazmak, sermek, döşemek, kaydetmek" (Öztürk, 2017: 129); YTS'de yazma $\perp$ (I) “1. Nakşetmek, resmetmek, süsleyip bezemek. 2. Yamak, dağıtmak, açmak” (Dilçin, 1983: 240).

yázı: EDPT'de yazı "geniş açık bir ova”, Osm. XIV. yüzyılda "büyük ova, çöl” (Clauson, 1972: 984); OY'de yazl "ova, step" (Tekin, 2010: 187); ETG'de yazl "ova, düzlük" (Gabain, 2007: 310); EUTS' de yazl "ova, düz yer" (Caferoğlu, 1968: 291); KB'de yazl "kır, ova" (Arat, 2008: 1275); DLT'de yazı "kır, ova, yazı, boş ve açık yer, boşluk, açıklık, alan" (Atalay, 1986: IV-765) yazı

\footnotetext{
21 Ladik (Samsun) ağzında bu kelime "yağını çıkarmak için yoğurdu yayıkta çalkalamak, sallamak" anlamında kullanılmıştır.

${ }^{22}$ Ladik (Samsun) ağzında bu kelime "yıkanmak, yıkamak" anlamında kullanılmıştır.
} 
"açık arazi, açıklık, kır, ova" (Ercilasun ve Akkoyunlu, 2015: 963); EATEK'de yazı "düzlük, meydan, mera açık alan" (Öztürk, 2017: 229); YTS'de yazı (I), [yazu (I)] "ova, sahra, 1ssız kır" (Dilçin, 1983: 240).

yi(g) ${ }^{23}$ : EDPT’de yég “daha iyi, üstün” (başka bir şeyden) (Clauson, 1972: 909); OY'de yig "daha iyi" (Tekin, 2010: 189); ETG'de yig, yeg "daha iyi, mükemmel" (Gabain, 2007: 311); EUTS'de yig "1. İyi, daha iyi. 2. Tercihen yeğ görüp. 3. Çiğ ham olmamış"; yigräk "daha iyi” (Caferoğlu, 1968: 295-296); KB'de yig "yeg, iyi, daha iyi” (Arat, 2008: 1278); DLT'de yég "yeğ, üst, üstün, daha iyi, hayırlı" (Atalay, 1986: IV-768) yig “"daha iyi' anlamında bir siz, yeğ" (Ercilasun ve Akkoyunlu, 2015: 974); NFD-S'de yeg "yeğ, tercih edilen, üstün tutulan" (Ata, 1998: 478); EATEK'de yig "daha iyi, şayan, tercih, yeğ” (Öztürk, 2017: 130); YTS'de yig (I), [yeg, yiy] "daha iyi, üstün. 2. Kuvvetli, baskın"; yigrek, [yegirek, yeğrek, yigirek] "daha iyi, üstün, baskın, tercih edilir." (Dilçin, 1983: 245).

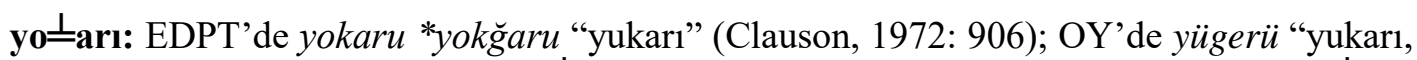
yukarıya" (Tekin, 2010: 192); ETG'de $y o \stackrel{\perp}{=} r u$ "yukarı" (Gabain, 2007: 312); EUTS'de yo $\perp_{a r u}$ "yukarı" (Caferoğlu, 1968: 301); KB'de yo $\Perp_{a r u}$ “yukarı" (Arat, 2008: 1280); DLT'de yokar, yokaru, yukaru, yokar "yukarı" (Atalay, 1986: IV-798) yokar, yokaru "yukarı" (Ercilasun ve Akkoyunlu, 2015: 980); YTS'de $y u \stackrel{\text { 上 }}{=}$ aru "yukarı" (Dilçin, 1983: 251).

yórí-/yörü-: EDPT'de yort- "yürümek" daha belirsiz "gitmek", "devam etmek (bir şey yapmaya)" (Clauson, 1972: 957); OY'de yort- "yürümek" (Tekin, 2010: 191); ETG'de yort-, yor-, yorri- yuorri- "yürümek" (Gabain, 2007: 312); EUTS'de yorıma $\perp$ "yürümek, gitmek, hareket etmek" (Caferoğlu, 1968: 302); KB'de yorl- "yürümek, varmak" (Arat, 2008: 1281); DLT'de yorl-, yor- "yürümek, gitmek, varmak; ismi yarıp ya1lmak; yürüyüp yorulmak" (Atalay, 1986: IV-802) yorl-, yoru-, yor- "yürümek" (Ercilasun ve Akkoyunlu, 2015: 981); NFD-S'de yöri-, yörü"yürümek, gezinmek, yoluna devam etmek; hareket etmek, davranmak; yaşamak, yaşamını devam ettirmek" (Ata, 1998: 489); EATEK'de yorl- "yürümek, ayakla hareket etmek, yol almak" (Öztürk, 2017: 130); YTS'de yortma $\perp$ "koşmak, sürekli yol yürümek"; yürümek [yürimek] "1. Gezmek, dolaşmak. 2. Hareket etmek, iş yapmak. 3. Tedavül etmek, geçer olmak. 4. Hareket etmek dönmek. 5. Hücum etmek, saldırmak. 6. Ayrılmak, uzaklaşmak. 7. Sözü geçmek." (Dilçin, 1983: 250, 255).

yu-: EDPT'de $y u$ - "yıkamak" daha belirsiz "gitmek", "devam etmek (bir şey yapmaya)" (Clauson, 1972: 870); ETG'de yu- "yıkamak, yumak" (Gabain, 2007: 313); EUTS'de yuma $\perp$ "y1kamak, temizlemek, kaldırmak" (Caferoğlu, 1968: 305); KB'de yu- "yıkamak" (Arat, 2008: 1282); DLT'de $y u$ - "yıkamak" (Atalay, 1986: IV-806) yzu "yıkamak" (Ercilasun ve Akkoyunlu, 2015: 984); NFD-S'de $y u$-, $y u w$-, $y u v$ - "yıkamak" (Ata, 1998: 490-491); EATEK'de $y u$ - "y1kamak,

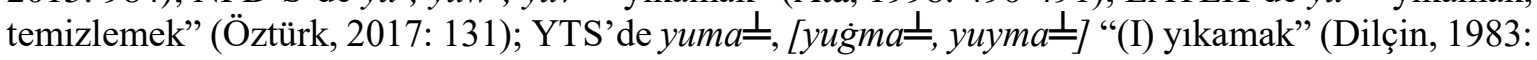
252).

\section{Sonuç}

1. Ses ve leksikoloji/söz varlığı yönüyle arkaik incelemesi yapılan Ladik (Samsun) ağzı taşıdığı dil özellikleri bakımından hem Oğuz hem de Kıpçak Türkçesinin özellikleri taşıdığı belirlenmiştir.

2. Eski Türkçede kelime başındaki ötümlü, süreksiz, patlayıcı /b/ ünsüzü ağızda korunmuştur; bol- "olmak" yine bu ağızda biş- "pişmek" şekliyle devam ettiği görülür.

3. Eski Türkçede kelime başındaki ötümsüz, süreksiz, patlayıcı /k/ ünsüzü ağızda korunmuştur; kel- "gelmek", kece "gece".

\footnotetext{
${ }^{23}$ Ladik (Samsun) ağzında bu kelime yirēydi <yig+rek+i-di şeklinde geçer. Anlamı ise “yeğrekti, üstündü” şeklindedir.
} 
4. Eski Türkçede kelime başındaki ötümlü, sürekli, akıcı /m/ ünsüzü ağızda korunmuştur; men "ben", $т и$ "bu".

5. Eski Türkçede kelime başındaki ötümsüz, süreksiz, patlayıcı /t/ ünsüzü ağızda korunmuştur; $t i$ - "demek", tol- "dolmak".

6. Eski Türkçedeki yuvarlaklaşmanın ağızda devam ettiği belirlenmiştir; berü "beri, öte", uçun, üçün "için".

7. Leksikoloji/söz varlığı açısından anlamların ağızda korunduğu belirlenmiştir.

\section{Kaynakça}

Abdizâde, H.E. (1927). Amasya Tarihi, C. 4, Necm-i İstikbal Matbaası Yayınları.

Arat, R. R. (2008). Kutadgu Bilig Yusuf Has Hacib, KabalcıYayınevi.

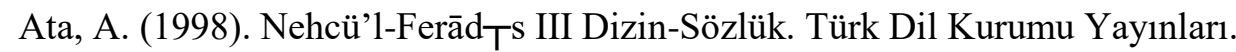

Atalay, B. (1986). Divanü Lûgat-it-Türk IV Dizini. Türk Dil Kurumu Yayınları.

Caferoğlu, A. (1968). Eski Uygur Türkçesi Sözlüğü. Enderun Kitabevi.

Clauson, S.G. (1972). An Etymological Dictionary of Pre-Thirteenth-Century Turkish, Oxford University Press.

Demir, N. (2000). “Karadeniz Bölgesi Ağızlarında Kıpçak Türkçesi Özellikleri”. IV. Uluslararası Türk Dili Kurultayı Bildirileri-I (24 Eylül-29 Eylül 2000) Ankara, 2007, 417-424.

Dilçin, C. (1983). Yeni Tarama Sözlüğü. Türk Dil Kurumu Yayınları.

Ercilasun, A.B. vd. (1991). Karşılaştırmalı Türk Lehçeleri Sözlüğü I-II. Kültür Bakanlığı Yayınları.

Ercilasun, A.B., Akkoyunlu Z. (2015). Kâşgarlı Mahmud Dîvânu Lugâti't- Türk (Giriş-MetinÇeviri-Notlar-Dizin). Türk Dil Kurumu Yayınları.

Ergin, M. (2009). Türk Dil Bilgisi. Bayrak Basım-Yayım-Tanıtım.

Gabain, A. V. (2007). Eski Türkçenin Grameri. Türk Dil Kurumu Yayınları.

Gemalmaz, E. (2010). “Ağız Bilimi Araştırmaları Üzerine Genellemeler.” Türkçenin Derin Yapısı, Belen Yayınc1lık, 331-349.

Karahan L. (1996) Anadolu Ağızlarının Sinıflandırılması, Türk Dil KurumuYayınları.

Korkmaz, Z. (2007). Gramer Terimleri Sözlüğ̈̈, Ankara: Türk Dil Kurumu Yayınları.

Korkmaz, Z. (2017). “Anadolu Ağızları Üzerindeki Araştırmaların Bugünkü Durumu ve Karşılaştığı Sorunlar.” Türk Dili Üzerine Araştırmalar, C. 1-2, Ankara: Türk Dil Kurumu Yayınları.

Kurşun, Z vd., (1999). Evliya Çelebi Seyahatnâmesi, C. 2, Yapı Kredi Yayınları.

Ölmez, M. (2003). "Çağataycadaki Eskicil Öğeler Üzerine.” Dil ve Edebiyat Araştırmaları Seтроzуити, Mustafa Canpolat Armağanı, 135-142.

Öner, M. (1998). Bugünkü Kıpçak Türkçesi. Türk Dil Kurumu Yayınları.

Öztürk, E. (2017). Eski Anadolu Türkçesi El Kitabı. Akçağ Yayınları.

Tellioğlu, İ. (2010). “Türklerin Karadeniz'e Çıkışında Vezirköprü-Havza-Ladik Hattının Önemi.” Atatürk Üniversitesi Edebiyat Fakültesi Sosyal Bilimler Dergisi Journal of Social Sciences, 10/45, 141-154. 
Tellioğlu, İ. (2014). “Samsun'a Türk Yerleşiminin Tarihî Gelişimi.”Turkish Studies - International Periodical For The Languages, Literature and History of Turkish or Turkic, 9/4, 1107-1117. https://doi.org/10.7827/turkishstudies.6758

Toparlı, R. vd. (2007). Kıpçak Türkçesi Sözlüğ̈̈. Türk Dil Kurumu Yayınları. 